\title{
Tolerant pearl millet (Pennisetum glaucum (L.) R. Br.) varieties to low soil $P$ have higher transpiration efficiency and lower flowering delay than sensitive ones
}

\author{
Francesca Beggi • Hamidou Falalou • \\ Andreas Buerkert • Vincent Vadez
}

Received: 19 May 2014 / Accepted: 17 November 2014 /Published online: 3 December 2014

(C) The Author(s) 2014. This article is published with open access at Springerlink.com

\begin{abstract}
Background and aim In the West African Sahel low soil phosphorus (P) and unpredictable rainfall are major interacting constraints to growth and grain yield of pearl millet. Investigating the relationship between transpiration and final yield under the combined effect of water and $\mathrm{P}$ stress is fundamental to understand the underlying mechanisms of tolerance and improve breeding programs.

Methods We conducted two lysimeter trials using $1 \mathrm{~m}$ long PVC tubes (35 cm diameter) filled with a $\mathrm{P}$ poor
\end{abstract}

Responsible Editor: Matthias Wissuwa.

Electronic supplementary material The online version of this article (doi:10.1007/s11104-014-2338-8) contains supplementary material, which is available to authorized users.

F. Beggi · A. Buerkert

Organic Plant Production and Agroecosystems Research in the Tropics and Subtropics, University of Kassel,

Witzenhausen, Germany

F. Beggi $\cdot$ H. Falalou

Sahelian Center, International Crops Research Institute for the Semi-Arid Tropics (ICRISAT),

Niamey, Niger

H. Falalou

Department of Biology, Faculty of Sciences, University

Abdou Moumouni,

Niamey, Niger

V. Vadez $(\bowtie)$

Crop Physiology Laboratory, International Crops Research

Institute for the Semi-Arid Tropics (ICRISAT),

Patancheru 502324 Telangana, India

e-mail: v.vadez@cgiar.org
Sahelian soil mimicking soil profiles to assess grain and stover yield, and water use of 15 pearl millet genotypes grown under different $\mathrm{P}$ (no $\mathrm{P}$ supply or addition of $1.5 \mathrm{~g}$ $\mathrm{P}$ tube ${ }^{-1}$ ) and water (well watered or terminal water stress) regimes. In experiment 2 transpiration was measured twice a week from tube weight differences, and transpiration efficiency (TE) was calculated as dry matter (DM) produced per $\mathrm{kg}$ of water transpired.

Results Low soil $\mathrm{P}$ delayed flowering, and more so in sensitive genotypes. Later flowering of genotypes sensitive to low $\mathrm{P}$ made them more sensitive to terminal water stress. Under P limiting soil, genotypes tolerant and sensitive to low $\mathrm{P}$ used similar amounts of water (19.8 and $21.7 \mathrm{~kg}$ water plant ${ }^{-1}$, respectively). However, tolerant lines transpired less water prior to anthesis $\left(8.8 \mathrm{~kg}\right.$ water plant $\left.{ }^{-1}\right)$ leaving more water available for grain filling (11 kg water plant $\left.{ }^{-1}\right)$ while sensitive lines used $14.4 \mathrm{~kg}$ water plant $^{-1}$ pre-anthesis, leaving only $7.2 \mathrm{~kg}$ water plant $^{-1}$ for grain filling. Low soil P decreased grain yield by affecting seed size at harvest and its damage during seed filling overrode the effect of seed size at sowing. Grain yield was positively correlated with water extracted after anthesis. TE was enhanced by $\mathrm{P}$ supply, especially in sensitive lines, and TE was higher in tolerant than in sensitive genotypes under low soil P.

Conclusions Pearl millet plants tolerant to low $\mathrm{P}$ were more resistant to the delay of flowering caused by low $\mathrm{P}$ soil and they presented higher transpiration efficiency. The pattern of transpiration was important to cope with terminal water stress under different levels of $\mathrm{P}$ availability. Higher transpiration after anthesis, resulting 
from conservative water mechanism pre-anthesis (higher TE) and possibly by a shorter delay in flowering under low soil $\mathrm{P}$, enhanced grain yield.

Keywords Water stress $\cdot$ Lysimeter $\cdot$ Transpiration efficiency. Water use

\section{Introduction}

Pearl millet (Pennisetum glaucum (L.) R. Br.) is the most important staple crop for millions of people in the semi-arid tropics of Africa (FAO and ICRISAT 1996). Sahelian farming systems are characterized by heavily weathered soils, low external inputs and continuous extraction of plant nutrients which, over centuries, have produced an extremely phosphorus $(\mathrm{P})$ poor soil, with values often below $5 \mathrm{mg}$ Bray- $\mathrm{P} \mathrm{kg}^{-1}$ soil (Bationo et al. 1990; Buerkert et al. 2000). In Niger the 4 months unimodal rainy season typically lasts from mid-May to mid-September, but precipitation is very scattered and often characterized by a late onset of the rains and midor end-season droughts. On the predominantly acid Arenosols dedicated to smallholder millet production, lack of rainfall and high temperatures (daily average temperature peaks in May at $34{ }^{\circ} \mathrm{C}$ and drops in December to $25^{\circ} \mathrm{C}$ (World Climate 2008)) quickly lead to major water stress for plants (Wallace et al. 1993). Low soil $\mathrm{P}$ and unpredictable water stress have for millennia been major interacting constraints to millet growth (Manu et al. 1991).

Phosphorus deficiency reduces leaf expansion (Fredeen et al. 1989), number of leaves (Lynch et al. 1991) and root development, which in turn affects the capacity of plants to uptake water from deeper soil horizons under low rainfall (Marschner 1995). Nevertheless, plant roots have developed several strategies to enhance P uptake under low moisture conditions with subsequent reduced diffusion, such as increased root length, length and number of root hairs, symbiosis with arbuscular mycorrhizal fungi (Gahoonia and Nielsen 2004; Liebersbach et al. 2004). In pearl millet, an enhancement of root hair formation was observed under Pdeficiency (Faye et al. 2006). Phosphorus-deficient Lotus japonicus showed lower root hydraulic conductivity due to a decreased expression of genes encoding aquaporins which explained the reduction of epidermal cell (and leaf) expansion (Clarkson et al. 2000). Other adaptive plant development responses to $\mathrm{P}$ deficiency comprise delay of flowering (Nord and Lynch 2008), decreased number of flowers (Bould and Parfitt 1973), inhibition of seed formation (Barry and Miller 1989) and premature leaf senescence, which all affect grain yield.

Despite numerous reports about the effects of $\mathrm{P}$ deficiency and water stress on millet growth (Manu et al. 1991; Buerkert 1995; Bagayoko et al. 2000; Brück et al. 2003; Valluru et al. 2009; Vadez et al. 2013), to our knowledge studies investigating the combination of both major stress factors on plant development are lacking, except few (Payne et al. 1990, 1992). The novelty of the present study is then in addressing this knowledge gap by using a lysimeter system consisting of large PVC tubes in which plants can be grown in a soil volume allowing soil exploration by the plant similar to field conditions, and where the effects of a factorial of $\mathrm{P}$ and water treatments can be investigated. The novelty of the approach is also in allowing to obtain highly relevant agronomic data in a system where the homogeneity of the soil can be controlled, whereas studies in low soil P field are often bound to face large field heterogeneity in $\mathrm{P}$ availability. Such a system has recently been used to assess water use throughout the cropping cycle until maturity in different crops (Ratnakumar and Vadez 2011; Vadez et al. 2011a; b; Zaman-Allah et al. 2011). It has also been tested to produce highly relevant agronomic data in low and high P soils (Karanam and Vadez 2010). The setup allows to determine transpiration efficiency (TE, calculated as dry matter (DM) produced per $\mathrm{kg}$ of water transpired) to distinguish tolerant and sensitive genotypes (Ratnakumar and Vadez 2011; Vadez et al. 2011a; b). It is well known that TE depends on interactions between water and nutrient availability (De Wit 1958; Tanner and Sinclair 1983; Clarkson et al. 2000; Vadez et al. 2014), and is particularly affected by nutrient deficiency (Payne 2000). For Sahelian conditions, Sivakumar and Salaam (1999) reported a $84 \%$ increase of water use efficiency in millet (WUE, grain yield per mm rain), of which TE is an important component, due to the addition of mineral fertilizers. Therefore, under limited water supply, plant nutrients may play an important role in enhancing WUE (Waraich et al. 2011), and more research is required to understand genotypic differences in TE under various levels of $\mathrm{P}$.

Seed size is a also a key determinant of evolutionary fitness in many species (Orsi and Tanksley 2009) and seed reserves govern $\mathrm{P}$ accumulation and root development (Zhu and Se 2001), which is fundamental to 
determine plant performance at early growth stages. That is why seed $\mathrm{P}$ concentration is often high in species that evolved on P poor soils (Groom and Lamont 2010). Higher seed P can contribute to higher tolerance to low $\mathrm{P}$ and this variable is often considered when evaluating genotypes for P efficiency (Liao and Yan 1999; Zhu and Se 2001).

Studies on millet genotypes contrasting for terminal water stress tolerance identified two watersaving mechanisms, which consist in maintaining a lower transpiration rate even at low vapour pressure deficit (VPD) and by further decreasing transpiration rate under higher VPD (Kholová et al. 2010a; 2010b). These mechanisms enhanced water availability during the reproductive and grain filling period, leading to higher grain yields under terminal stress (Vadez et al. 2013). Similar effects of water stress during periods critical for grain yield formation have been reported for chickpea (Zaman-Allah et al. 2011), sorghum (Hammer et al. 2006) and cowpea (Belko et al. 2012). Because low soil $\mathrm{P}$ condition are known to delay flowering, the combination of a water and a low $\mathrm{P}$ stress is therefore likely to modify the proportion of water used before and after anthesis, and then to have possible negative consequences on the grain filling.

The first hypothesis of this work was that the low soil $\mathrm{P}$ conditions would alter the phenological development and the water use efficiency of the crops in ways that could explain part of the genotypic differences in the yield under low soil $\mathrm{P}$ conditions. The other hypothesis was that differences in plant development and growth under low soil $\mathrm{P}$ would alter the kinetics of plant water use and would then have profound effects on the plant response to water limitation. The objectives of this work were then three-folds: (i) to assess the effect of low soil phosphorus on the agronomic attributes, including flowering time, of a set of pearl millet genotypes; (ii) to monitor the kinetics of plant water use in a factorial of $\mathrm{P}$ and water treatments and assess the effect of low soil $\mathrm{P}$ on the pre- and post-anthesis water use; (iii) to measure the impact of low soil $\mathrm{P}$ on transpiration efficiency (TE). These analyses were done in pearl millet genotypes that turned out to contrast for the seed yield under low soil $\mathrm{P}$ conditions, allowing us to infer some general trends of plant attributes characterizing low soil $\mathrm{P}$ tolerance in pearl millet.

\section{Materials and methods}

Experimental conditions

Two experiments with 15 West African pearl millet varieties each were carried out: Experiment 1 (Exp. 1) was conducted between December 2010 and March 2011 and Experiment 2 (Exp. 2) between September and December 2012 (Table 1). The 15 genotypes grown in Exp. 1 were selected from a collection of 102 genotypes according to their contrasting vegetative biomass production at 5 weeks after sowing in pot trials during the rainy season of 2010. The same procedure was applied to select the 15 genotypes for Exp. 2, based on results of a pot trial run during the 2011 rainy season. In Exp. 1, seeds were sown on 23 December 2010 at a rate of 4-5 seeds per pocket and 3 pockets per tube. During the cropping period, the maximum and minimum temperatures ranged from 32.1 to $41.1{ }^{\circ} \mathrm{C}$ and 16.0 to $24.0{ }^{\circ} \mathrm{C}$, respectively, and relative air humidity at $1 \mathrm{pm}$ averaged 12 \% (January-March 2011). In Exp. 2, seeds were sown on 27 September 2012 at the same rate as in Exp. 1. During the cropping period, maximum and minimum temperatures ranged from 33.4 to $38.3{ }^{\circ} \mathrm{C}$ and 17.2 to $23.3^{\circ} \mathrm{C}$, respectively, and relative humidity of the air at $1 \mathrm{pm}$ decreased from $90 \%$ (September) to $13 \%$ (December). The same lysimeters were used in Exp. 1 and Exp. 2, and soil was not replaced between trials, though first cereals (pearl millet and sorghum) and then a legume (cowpea) were grown in the cylinders between the two trials.

\section{Description of lysimeters and soil preparation}

The lysimeters consisted of PVC cylinders filled with the topsoil of a severely P deficient Arenosol (Bray-P $<5 \mathrm{mg} \mathrm{P} \mathrm{kg}^{-1}$ soil) from the ICRISAT Sahelian Centre at Sadoré, Niger. These tubes $(35 \mathrm{~cm}$ diameter, $100 \mathrm{~cm}$ height) yielded a plant spacing of 4-5 plants $\mathrm{m}^{-2}$. The bottom of the tube consisted in a PVC plate maintained on top of four screws. Water drainage could take place between the PVC plate and the inner wall of the tube, although soil could not slip through. All lysimeters were placed upright in $1 \mathrm{~m}$ deep trench, over which the weighing mechanism could be moved to select individual cylinders for weighing (Exp. 2 only). The tops of the cylinders were equipped with metal collars and chains to allow the lysimeters to be lifted and weighed. The lysimeter weighting procedure involved a crane balance 
Table 1 Genotype identification number, full variety name, selection category and country of origin of the 15 pearl millet genotypes grown in lysimeters in 2010 and 2012

\begin{tabular}{|c|c|c|c|c|}
\hline Trial & Genotype identification number & Variety name & Category & Origin \\
\hline \multirow[t]{15}{*}{2010} & 1 & PE06001 & Landrace & Burkina Faso \\
\hline & 2 & PE00077 & Landrace & Cameroun \\
\hline & 3 & PE00397 & Landrace & Mali \\
\hline & 4 & CZ Boboni-Sanougoula & Breeding variety & Mali \\
\hline & 5 & SOSAT_C88_Check_all & Breeding variety & Mali-IER-ICRISAT \\
\hline & 6 & PE08057 & Landrace & Mauritania \\
\hline & 7 & PE08058 & Landrace & Mauritania \\
\hline & 8 & PE02724 & Landrace & Niger \\
\hline & 9 & ICMV IS 94206 & Breeding variety & Niger-ICRISAT \\
\hline & 10 & Striga_res_expvar_epis_long_noir & Breeding variety & Niger-ICRISAT \\
\hline & 11 & M66xSosat_C1_Sad_Low_2009 & Breeding variety & NigerxMali \\
\hline & 12 & PE03089 & Landrace & Senegal \\
\hline & 13 & PE03012 & Landrace & Senegal \\
\hline & 14 & GB8735xMoro_C1_PF_SAD & Breeding variety & SenegalxNiger \\
\hline & 15 & Sadore Local_check_1 & Landrace & Niger \\
\hline \multirow[t]{15}{*}{2012} & 1 & GB8735xMoro_C1_PF_SAD & Breeding variety & SenegalxNiger \\
\hline & 2 & 2898x92222_C1_Sad_Low_2009 & Breeding variety & NigerxNiger \\
\hline & 3 & PE05387 & Landrace & Mali \\
\hline & 4 & StrigaRes_2009_Sad_Cinz_comb & Breeding variety & Niger-ICRISAT \\
\hline & 5 & SOSAT_C88_Check_all & Breeding variety & Mali-IER-ICRISAT \\
\hline & 6 & PE03089 & Landrace & Senegal \\
\hline & 7 & Madougou5 & Landrace & Mali \\
\hline & 8 & Serkin_C2_Kandela_SMS & Breeding variety & NigerxNiger \\
\hline & 9 & Striga_res_expvar_epis_long_noir & Breeding variety & Niger-ICRISAT \\
\hline & 10 & ICMVIS94206 & Breeding variety & Niger-ICRISAT \\
\hline & 11 & PE08030(“SounaMau”) & Landrace & Mauritania \\
\hline & 12 & Doga_C2_PF_comb & Breeding variety & Niger \\
\hline & 13 & Tera_C2_PF_comb & Breeding variety & Niger \\
\hline & 14 & Serkin_C2_Ali_SMS2 & Breeding variety & Niger \\
\hline & 15 & Ankoutess & Breeding variety & Niger-ICRISAT \\
\hline
\end{tabular}

In bold: genotypes used in both trials. Category Breeding variety refers to improved varieties

(S-type load cell with a $200 \mathrm{~kg}$ load capacity; MettlerToledo, Geneva, Switzerland) connected to a blockchained pulley to lift the tubes. The scale allowed repeated measurements at an accuracy of $\pm 20 \mathrm{~g}$.

In order to mimic a low $\mathrm{P}$ profile, we collected top soil $(0-0.2 \mathrm{~m})$ and subsoil $(0.2-0.8 \mathrm{~m})$ from a low $\mathrm{P}$ field. The top soil had the following characteristics: 5.5 $\mathrm{pH}_{\mathrm{H} 2 \mathrm{O}}(1: 2.5), 3.7 \mathrm{mg}$ Bray-P kg ${ }^{-1}$ soil, Corg 0.3\%, $247.4 \mathrm{mg}$ total $\mathrm{N} \mathrm{kg}^{-1}$ soil. The bulk soil was characterized as follows: $5.8 \mathrm{pH}_{\mathrm{H} 2 \mathrm{O}}(1: 2.5), 3.6 \mathrm{mg}$ Bray- $\mathrm{P} \mathrm{kg}^{-1}$ soil, Corg $0.1 \%, 81 \mathrm{mg}^{2}$ total $\mathrm{N} \mathrm{kg}^{-1}$ soil. Both soil types were kept separate and brought back to the farm, air- dried and homogenized thoroughly prior to filling the tubes with $95 \mathrm{~kg}$ subsoil and then $25 \mathrm{~kg}$ topsoil, leaving the upper $0.15 \mathrm{~m}$ of the tubes empty to allow for the application of a layer of anti-evaporation beads and for watering.

Treatment application and water extraction measurements

Two $\mathrm{P}$ treatments were used in each of the two experiments. The high P (HP) treatment in Exp. 1 consisted of applying $300 \mathrm{mg}$ DAP $\mathrm{kg}^{-1}$ topsoil, i.e. $7.5 \mathrm{~g}$ DAP 
tube $^{-1}$ applied in a circle $2-3 \mathrm{~cm}$ around the seedling area after emergence. The low P (LP) lysimeters did not receive any $\mathrm{P}$ application, but were supplied with urea to compensate for DAP nitrogen input into HP tubes (3.45 $\mathrm{g}$ urea applied in two doses: $2 \mathrm{~g}$ after emergence and 1.5 g 3-4 weeks after sowing). For Exp. 2 in 2012, no application of $\mathrm{P}$ was necessary because the soil in the Exp. $1 \mathrm{HP}$ tubes from 2010 was still rich in available $\mathrm{P}$ (32.8 $\mathrm{mg} \mathrm{P} \mathrm{g}^{-1}$ soil). A top dressing dose of $2.5 \mathrm{~g}$ urea was applied on all the cylinders in Exp. 2 at 23 day after sowing (DAS). Millet plants were grown until maturity in both experiments, in Exp. 1, only one well-watered (ww) treatment was applied, whereas in Exp. 2, both a ww treatment and a water stress (ws) treatment were used. Transpiration was measured in Exp. 2 only.

In both experiments, seedlings were thinned to three plants per tube at 14 DAS and to one plant per tube at 25 DAS. Soil was kept at $90 \%$ of field capacity by weighing the tubes every 4 days, measuring the amount of water lost by evapotranspiration and compensating by proper rewatering.

In Exp. 1 the experimental design was a randomized complete block design with LP and HP treatments at either side of the trench in which all the tubes were placed in order to avoid HP plants shading the LP plants. The 15 genotypes randomized within each of the five repetitions (blocks). In Exp. 2 we used a design with $P$ treatment as the main plot and water treatment as the sub-plots, the 15 genotypes were randomized 6 times within each sub-plot giving a four treatment factorial: LPws, LPww, HPws and HPww, where: LP=low P, $\mathrm{HP}=$ high $\mathrm{P}, \mathrm{ww}=$ well watered and $\mathrm{ws}=$ water stressed.

In Exp. 2, we assessed plant transpiration as a proxy for plant growth. Thus, at $35 \mathrm{DAS}$, the soil surface was covered with a round plastic sheet superposed with a 2$\mathrm{cm}$ layer of low-density polyethylene beads to prevent soil evaporation. The lysimeters were weighted every 4 days from 36 DAS to 81 DAS yielding a total of 12 measurements $(39,43,46,50,54,57,61,64,67,70,74$ and 77 DAS). Water extraction related to plant transpiration was calculated from cylinder weight differences between consecutive weighings and additions of water. Transpiration data were assigned to the latest weighing so that e.g. transpiration at 50 DAS refers to the water transpired by the plant in the interval between 47 and 50 DAS.

In Exp. 2 all plants were irrigated until 57 DAS. There were altogether $180 \mathrm{LP}$ tubes and $180 \mathrm{HP}$ tubes (15 genotypes by 12 replicated tubes per genotype). Then both HP and LP treatments were split into a well watered (ww) and water stressed (ws) treatments. The ws treatment consisted in omitting irrigation in 90 LP and $90 \mathrm{HP}$ tubes, from $57 \mathrm{DAS}$ to $74 \mathrm{DAS}$. This gave a 17 days period of terminal stress consistent with similar situation in the field. However, the transpiration measurements between 57 and 74 DAS allowed us to monitor carefully the stress intensity (by assessing the ratio of transpiration values under WS and WW conditions). As such, at 74 DAS the transpiration of WS plants fell below $30 \%$ of that in WW plants and it was decided to apply a $2 \mathrm{~L}$ watering per cylinder, which was also the final one. The $180 \mathrm{ww}$ tubes (90 LP and $90 \mathrm{HP}$ ) were kept regularly watered until maturity of pearl millet.

Harvest procedure and statistical analysis

The seeds used for sowing were previously stored in the genebank of ICRISAT Sahelian Centre and produced under optimal conditions. The size of sown and harvested seeds was measured as the weight (g) of 100 seeds. Growth parameters were measured weekly and included height, number of tillers and number of leaves. Booting and flowering time (d) were recorded for the main stem in each tube. Phosphorus concentration ( $\left.\mathrm{mg} \mathrm{g}^{-1} \mathrm{DM}\right)$ in plant tissues was measured colorimetrically on the main stem's flag leaf at the time of its appearance in Exp. 2. Plants were harvested at maturity at soil level starting from 83 DAS onwards, and all the material was sun dried to constant weight in cotton bags.

Stover yield was calculated as the sum of leaves and stem; the total dry weight (TDM) was the stover yield plus the spike weight and total yield was the stover yield plus grain yield.

The panicle harvest index (PHI) was calculated by dividing the grain yield ( $\mathrm{g}$ ) by the total panicle biomass (g). In Exp. 2, water uptake in the pre- and post-anthesis period was calculated for each plant by summing transpiration values before and after flowering. Transpiration efficiency (TE) was then calculated as the ratio of the total biomass produced (grain and stover) per $\mathrm{kg}$ of water transpired ( $\left.\mathrm{g} \mathrm{kg}^{-1} \mathrm{WU}\right)$. In this study, root biomass was not measured, that is why TE assessments were based only on shoot dry matter and thus slightly underestimated. However, in earlier studies, we found that omitting the roots was not likely to alter the genotypic ranking (Vadez et al. 2011a, b).

Data were statistically analyzed by one- and two-way ANOVA using $\mathrm{R}$ at $p<0.05(*), p<0.01(* *)$ and $p<0.001(* * *)$. As regression analysis we conducted a 
simple linear regression to assess the relationship between our variables.

\section{Residual yields as a tool for measuring tolerance to low $P$}

In case of lack of genotype-by-treatment interaction (GxTrt) for yield components, yield performance under LP could not be attributed to the P tolerance of genotypes alone, but to a grain or stover yield potential component plus a residual yield variation. This residual would then account for tolerance to low $\mathrm{P}$ per se plus an error component, and represent the part of variation in yield under LP that is not explained by grain or stover yield potential (Vadez et al. 2007; Bidinger et al. 1987). In this study these residuals were calculated as the difference between the observed yield values under LP and the predicted ones from the linear regression model (LP vs. HP) and they were used as proxy for tolerance to low P.

\section{Results}

Low P (LP) effect on agronomic traits under well watered (ww) conditions

The total yield of LPww plants was 44 and $41 \%$ lower than that of HPww plants in Exp 1 and 2, respectively (Table $2 \mathrm{a}$ and $\mathrm{b}$ ). Grain yields of LPww plants reached 39 and $66 \%$ of grain yields of HPww plants in Exp. 1 and Exp. 2, respectively. The LPww treatment dramatically reduced seed size (100-seed weight) from 0.72 (HPww) to $0.49 \mathrm{~g}$ (LPww) in Exp. 1 (Table 2a), and from $0.61 \mathrm{~g}$ (HPww) to $0.50 \mathrm{~g}$ (LPww) in Exp.2 (Table 2b). The onset of flowering was delayed by 2 weeks in the LP treatment in Exp. 1, which was not the case in the Exp. 2 trial, when flowering varied only among genotypes but not between treatments (Table 2b). This could be due to a forced flowering under short days in this September to December trial. In general, all yield components (except for HI and panicle HI in Exp. 2) decreased under LPww, and the majority of these traits differed also among genotypes within treatment (Table $2 \mathrm{a}$ and $\mathrm{b}$ ). None of the parameters showed any genotype-by-treatment interaction.

In Exp. 2, the grain yield varied from 4.13 to $13.85 \mathrm{~g}$ among genotypes under LPww (Table 3). This genetic variation was taken into account to select contrasting genotypes: 4 low $\mathrm{P}$ tolerant $(\mathrm{T})$ with significantly higher grain yield under LPww and 3 low P sensitive (S) with lower grain yield under LPww (Table 3), although genotype number 14 was different from the tolerant group at $p<0.1$. These groups of "tolerant" and "sensitive" genotypes (as we will refer to in this paper) were meant to analyse possible plant attributes explaining the difference in performance under low soil $\mathrm{P}$.

Flag leaf $\mathrm{P}$ concentration did not discriminate the tolerant from the sensitive group of genotypes. Genotypic differences in flag leaf $\mathrm{P}$ concentration were not due to a dilution effect as there was no correlation between the $\mathrm{P}$ concentration and dry weight. Under HPww treatment, the flag leaf $\mathrm{P}$ concentration was positively related to transpiration efficiency $(\mathrm{r}=0.520, p<0.05)$ and to grain yield ( $\mathrm{r}=0.642, p<0.01$, data not shown).

Low P (LP) effect on agronomic traits under water stressed (ws) conditions

In Exp. 2, grain yield varied from 2.24 to $11.86 \mathrm{~g}$ (Table 3). Grain yields under LPws were higher $(5.7 \mathrm{~g}$ ) than under HPws ( $4.9 \mathrm{~g}$; Table $2 \mathrm{~b}$ and $\mathrm{c}$ ). This was in part because the drought stress effect in the larger HPws plants was more severe. Under ws conditions, seed size, $\mathrm{HI}$ and panicle $\mathrm{HI}$ were also significantly lower in HPws than in LPws, which could indeed be seen in the increased failure in seed set. We observed a large genotypic variation under LP. Among the tolerant genotypes identified under LPww conditions, only genotype 3 and 7 were also the higher yielding under LPws conditions (Table 3). Under these conditions of combined low soil P and water stress, the group of sensitive genotypes produced just $40 \%$ of the grain yield of tolerant ones (Table 3).

Flag leaf $\mathrm{P}$ concentration did not discriminate tolerant from sensitive lines in any of the four treatments. Phosphorus concentration in the flag leaf was calculated in Exp. 2 where it ranged from $0.3 \mathrm{mg} \mathrm{P} \mathrm{g} \mathrm{DM}^{-1}$ (LP) to $0.5 \mathrm{mg} \mathrm{P} \mathrm{g} \mathrm{DM}^{-1}$ (HP) being then lower in the LPws than in the HPws treatment (Tables 3 and 4). Flag leaf $P$ concentration was positively associated with transpiration efficiency $(\mathrm{r}=0.521, p<0.05)$ and with grain yield $(\mathrm{r}=0.730, p<0.01$, data not shown) under HPws.

Low P tolerance index and relationship to flowering delay under low $\mathrm{P}$

A significant linear relationship was found between the grain yield in LP and HP treatments in Exp. 1 under ww conditions and in Exp. 2 under ws conditions (Fig. 1a and 


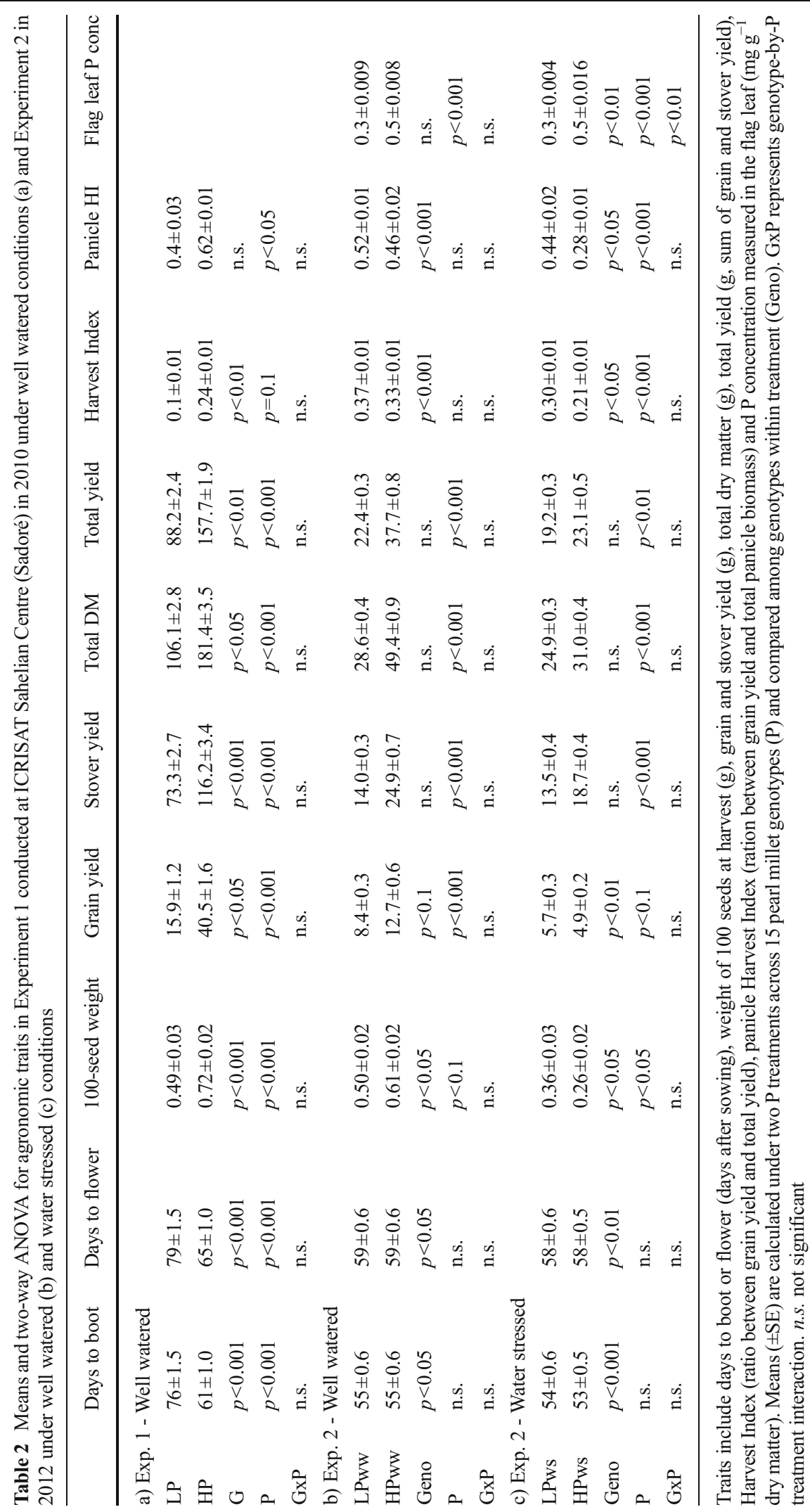


Table 3 Yield components and water uptake traits of 15 pearl millets genotypes tested under LPww and LPws in Experiment 2 conducted at ICRISAT Sahelian Centre (Sadoré) in 2012

\begin{tabular}{|c|c|c|c|c|c|c|c|c|c|c|}
\hline & Genotype & Type & $\begin{array}{l}\text { Flag leaf } \\
\mathrm{P} \text { conc } \\
\left(\mathrm{mg} \mathrm{g}^{-1} \mathrm{DM}\right)\end{array}$ & $\begin{array}{l}\text { Grain } \\
\text { yield } \\
(\mathrm{g})\end{array}$ & $\begin{array}{l}\text { Total } \\
\text { DM } \\
(\mathrm{g})\end{array}$ & $\begin{array}{l}\text { Total WU } \\
\left(\mathrm{kg} \mathrm{plant}^{-1}\right)\end{array}$ & $\begin{array}{l}\text { Pre-anthesis } \\
\text { WU } \\
\left(\mathrm{kg} \mathrm{plant}^{-1}\right)\end{array}$ & $\begin{array}{l}\text { Post-anthesis } \\
\text { WU } \\
\left(\mathrm{kg} \mathrm{plant}^{-1}\right)\end{array}$ & $\begin{array}{l}\text { TE } \\
\left(\mathrm{g} \mathrm{kg}^{-1} \mathrm{WU}\right)\end{array}$ & PHI \\
\hline \multirow[t]{19}{*}{ LPww } & 1 & & 0.24 & 8.15 & 24.77 & 17.42 & 8.61 & 8.81 & 1.40 & 0.61 \\
\hline & 2 & $\mathrm{~T}$ & 0.21 & 13.85 & 37.18 & 24.60 & 12.28 & 12.32 & 1.50 & 0.64 \\
\hline & 3 & $\mathrm{~T}$ & 0.29 & 11.42 & 27.70 & 17.02 & 4.95 & 12.07 & 1.62 & 0.67 \\
\hline & 4 & & 0.21 & 7.73 & 27.47 & 19.89 & 12.11 & 7.78 & 1.36 & 0.57 \\
\hline & 5 & & 0.30 & 6.69 & 22.00 & 16.50 & 8.27 & 8.23 & 1.31 & 0.55 \\
\hline & 6 & $\mathrm{~T}$ & 0.23 & 11.87 & 33.45 & 21.24 & 12.78 & 8.46 & 1.52 & 0.62 \\
\hline & 7 & $\mathrm{~T}$ & 0.26 & 11.18 & 26.06 & 16.31 & 5.15 & 11.16 & 1.57 & 0.70 \\
\hline & 8 & & 0.22 & 7.79 & 29.84 & 20.03 & 13.14 & 8.03 & 1.47 & 0.43 \\
\hline & 9 & $\mathrm{~S}$ & 0.22 & 4.13 & 25.86 & 21.16 & 14.93 & 6.23 & 1.22 & 0.35 \\
\hline & 10 & $\mathrm{~S}$ & 0.24 & 5.22 & 26.34 & 23.29 & 16.50 & 6.28 & 1.14 & 0.46 \\
\hline & 11 & & 0.19 & 8.11 & 29.55 & 21.13 & 11.93 & 9.19 & 1.38 & 0.57 \\
\hline & 12 & & 0.21 & 10.58 & 27.33 & 16.89 & 7.46 & 9.43 & 1.65 & 0.53 \\
\hline & 13 & & 0.23 & 4.33 & 24.79 & 19.81 & 12.19 & 7.62 & 1.24 & 0.42 \\
\hline & 14 & $\mathrm{~S}$ & 0.20 & 6.42 & 28.97 & 20.77 & 11.71 & 9.07 & 1.38 & 0.41 \\
\hline & 15 & & 0.20 & 7.90 & 28.17 & 19.86 & 11.34 & 8.51 & 1.41 & 0.48 \\
\hline & LSD & $0.09 *$ & $5.8^{*}$ & n.s. & n.s. & $4.16^{* *}$ & n.s. & n.s. & $0.22 * * *$ & \\
\hline & mean & $\mathbf{T}$ & 0.25 & 12.08 & 31.09 & 19.79 & 8.79 & 11.00 & 1.55 & 0.66 \\
\hline & mean & $\mathbf{S}$ & 0.22 & 5.26 & 27.06 & 21.74 & 14.38 & 7.19 & 1.25 & 0.38 \\
\hline & & & n.s. & $p<0.001$ & n.s. & n.s. & $p<0.001$ & $p<0.05$ & $p<0.001$ & $p<0.001$ \\
\hline \multirow[t]{23}{*}{ LPws } & 1 & & 0.25 & 5.83 & 26.72 & 19.41 & 11.64 & 7.84 & 1.37 & 0.48 \\
\hline & 2 & $\mathrm{~T}$ & 0.19 & 6.60 & 27.30 & 20.66 & 10.58 & 10.08 & 1.30 & 0.46 \\
\hline & 3 & $\mathrm{~T}$ & 0.30 & 10.03 & 21.90 & 13.78 & 4.69 & 9.09 & 1.57 & 0.71 \\
\hline & 4 & & 0.30 & 4.09 & 23.92 & 18.17 & 13.53 & 4.65 & 1.30 & 0.26 \\
\hline & 5 & & 0.27 & 7.57 & 23.27 & 17.07 & 9.13 & 7.94 & 1.36 & 0.62 \\
\hline & 6 & $\mathrm{~T}$ & 0.22 & 5.26 & 24.97 & 17.93 & 11.09 & 6.84 & 1.40 & 0.40 \\
\hline & 7 & $\mathrm{~T}$ & 0.27 & 11.86 & 29.20 & 18.48 & 5.26 & 13.21 & 1.59 & 0.65 \\
\hline & 8 & & 0.24 & 3.35 & 27.63 & 20.88 & 12.97 & 7.91 & 1.32 & 0.28 \\
\hline & 9 & S & 0.24 & 2.24 & 26.00 & 19.72 & 14.76 & 4.96 & 1.32 & 0.23 \\
\hline & 10 & $\mathrm{~S}$ & 0.21 & 3.90 & 28.30 & 21.76 & 15.46 & 6.30 & 1.32 & 0.31 \\
\hline & 11 & & 0.23 & 7.19 & 29.13 & 18.80 & 10.77 & 8.04 & 1.54 & 0.50 \\
\hline & 12 & & 0.27 & 4.40 & 15.51 & 12.36 & 7.94 & 4.42 & 1.27 & 0.51 \\
\hline & 13 & & 0.26 & 6.77 & 26.60 & 19.79 & 12.32 & 7.47 & 1.33 & 0.46 \\
\hline & 14 & $\mathrm{~S}$ & 0.29 & 3.84 & 21.71 & 20.94 & 15.01 & 4.71 & 1.06 & 0.50 \\
\hline & 15 & & 0.24 & 3.31 & 21.56 & 16.25 & 11.74 & 4.51 & 1.40 & 0.32 \\
\hline & LSD & n.s & $5.2^{*}$ & n.s & n.s. & $4.74 * *$ & $4.11 * *$ & n.s & n.s & \\
\hline & mean & $\mathbf{T}$ & 0.24 & 8.44 & 25.84 & 17.71 & 7.90 & 9.81 & 1.46 & 0.55 \\
\hline & mean & $\mathbf{S}$ & 0.25 & 3.33 & 25.34 & 20.81 & 15.08 & 5.32 & 1.23 & 0.29 \\
\hline & & & n.s. & $p<0.05$ & n.s. & n.s. & $p<0.05$ & $p<0.05$ & $p<0.001$ & $p<0.001$ \\
\hline & LPww & $0.3 \pm 0.009$ & $8.4 \pm 0.3$ & $28.6 \pm 0.4$ & $19.7 \pm 0.5$ & $10.80 \pm 0.5$ & $8.92 \pm 0.4$ & $1.41 \pm 0.03$ & $0.52 \pm 0.01$ & \\
\hline & LPws & $0.3 \pm 0.004$ & $5.7 \pm 0.3$ & $24.9 \pm 0.3$ & $18.4 \pm 0.4$ & $11 \pm 0.5$ & $7.2 \pm 0.4$ & $1.4 \pm 0.03$ & $0.44 \pm 0.02$ & \\
\hline & G & n.s. & $p<0.05$ & n.s. & n.s. & $p<0.05$ & $p<0.05$ & $p<0.1$ & $p<0.05$ & \\
\hline & $\mathbf{W}$ & $p<0.1$ & $p<0.001$ & $p<0.005$ & $p<0.05$ & n.s. & $p<0.05$ & n.s. & $p<0.05$ & \\
\hline
\end{tabular}


Table 3 (continued)

\begin{tabular}{|c|c|c|c|c|c|c|c|c|c|}
\hline Genotype & Type & $\begin{array}{l}\text { Flag leaf } \\
\text { P conc } \\
\left(\mathrm{mg} \mathrm{g} \mathrm{g}^{-1}\right. \\
\mathrm{DM})\end{array}$ & $\begin{array}{l}\text { Grain } \\
\text { yield } \\
(\mathrm{g})\end{array}$ & $\begin{array}{l}\text { Total } \\
\text { DM } \\
\text { (g) }\end{array}$ & $\begin{array}{l}\text { Total WU } \\
\left(\mathrm{kg} \text { plant }{ }^{-1}\right)\end{array}$ & $\begin{array}{l}\text { Pre-anthesis } \\
\text { WU } \\
\left(\text { kg plant }^{-1}\right)\end{array}$ & $\begin{array}{l}\text { Post-anthesis } \\
\text { WU } \\
\left(\mathrm{kg} \mathrm{plant}^{-1}\right)\end{array}$ & $\begin{array}{l}\text { TE } \\
\left(\mathrm{g} \mathrm{kg}{ }^{-1}\right. \\
\text { WU })\end{array}$ & PHI \\
\hline GxW & n.s. & n.s. & n.s. & n.s. & n.s. & n.s. & n.s. & n.s. & \\
\hline
\end{tabular}

$T$ and $S$ are tolerant and sensitive genotypes selected according to their contrasting performance across LPww and LPws. Water use refers to transpiration. Parameters include P concentration measured in the flag leaf ( $\mathrm{mg} \mathrm{g}^{-1}$ dry matter), grain yield (g), total dry matter (g), total WU (total water used during the trial), pre-anthesis WU (water used before flowering), post-anthesis WU (water used after flowering), TE (transpiration efficiency) and PHI (panicle harvest index). One-way ANOVA was used to determine least significant differences (LSDs) and differences between T and S genotypes. Two-way ANOVA was used to test differences among genotypes (Geno), between water treatments (W) and genotype-by-W treatment (GxW) interaction. Different levels of significance $(p<0.05 *, p<0.01 * *, p<0.001 * * *)$ have been considered. n.s. not significant

c), and also between stover yield in LP and HP treatments in Exp. 1 and in Exp. 2 under both ws and ww conditions (Fig. 1a, b and c) (Supplementary Table 1 for detailed flowering and booting data). As there was no genotypeby-treatment interaction (GxTrt) for these traits, the residuals calculated from the linear regression model between grain yield under LP and grain yield under HP (Fig. 1a and b) were used as proxy for tolerance to low P. In Exp. 1 LPww and Exp. 2 LPws higher residuals were in fact related to increasing absolute grain yield values $(\mathrm{r}=0.710$ and $\mathrm{r}=0.759$ respectively, $p<0.001)$. However, genotypes with highest residual grain yield did not correspond to those with the highest residual stover yield because both trials showed a clear negative association between seed and total biomass production $(\mathrm{r}=0.862$, $p<0.001$ in Exp. 1 and $\mathrm{r}=0.630, p<0.05$ in Exp. 2, data not shown). In relation to the residual grain yield in Exp. 2 water stressed (Fig. 1c), because of the strong effect of the water stress in grain yield under HP conditions, these residual were likely to account for a combination of low soil $\mathrm{P}$ tolerance and drought tolerance, and not only low soil P tolerance as in Exp.1.

In Exp. 1 delay in booting or flowering under LP was then negatively and highly significantly correlated with the residual grain yield (Fig. 2). In Exp. 2, there was also a negative relationship between the delay in flowering under ws conditions, although this could have been related in part to late flowering entries having lower yield under stress (data not shown).

Relationship between water uptake and yield components and link to pre- and post-anthesis water use

Total water transpired, measured from 39 DAS to maturity (77 DAS), differed significantly among the four treatments and varied from $18.4 \mathrm{~kg} \mathrm{plant}^{-1}$ in the LPws treatment to $26.4 \mathrm{~kg} \mathrm{plant}^{-1}$ in the HPww treatment $(p<0.001)$. The decrease in water transpiration after water stress imposition was more pronounced under HP than under LP conditions because of the larger size of HP plants (Fig. 3). Under both ww and ws conditions, the water use over time of sensitive lines was generally above that of tolerant lines, with greater differences under ww conditions (Fig. 3). Despite this, the total water use did not differ significantly between tolerant and sensitive genotypes in any of the four treatments combinations (Tables 3 and 4). Nevertheless, tolerant genotypes 3 and 7 that had the lowest plant water use across water treatment.

In fact, large differences were found between the tolerant and sensitive groups of genotypes in the water use before and after flowering (Fig. 4). Under LPww conditions, sensitive genotypes used $14.4 \mathrm{~kg}$ water per plant pre-anthesis while tolerant genotypes transpired almost $40 \%$ less, thus leaving more water in the soil for use post-anthesis (Table 3). Under LPww conditions, the total water use of tolerant and sensitive groups was similar, although the post-anthesis water use value of the tolerant group was about $4 \mathrm{~L}$ above that of the sensitive group. A similar situation occurred under LPws, where the tolerant group used significantly lower amount of water in the pre-anthesis period than the sensitive group and, reversely, the tolerant group used significantly higher amount of water in the post-anthesis period than the sensitive group (Table 3). Hence under both LPww and LPws, the pre- and post-anthesis water use differed between tolerant and sensitive genotypes (Table 3, Fig. 4), although this could have been related to the later 
Table 4 Yield components and water uptake traits of 15 pearl millets genotypes tested under HPww and HPws in Experiment 2 conducted at ICRISAT Sahelian Centre (Sadoré) in 2012

\begin{tabular}{|c|c|c|c|c|c|c|c|c|c|c|}
\hline & Genotype & Type & $\begin{array}{l}\text { Flag leaf } \\
\text { P conc } \\
\left(\mathrm{mg} \mathrm{g}^{-1} \mathrm{DM}\right)\end{array}$ & $\begin{array}{l}\text { Grain } \\
\text { yield } \\
(\mathrm{g})\end{array}$ & $\begin{array}{l}\text { Tot DM } \\
(\mathrm{g})\end{array}$ & $\begin{array}{l}\text { Total } \\
\text { WU } \\
\left(\mathrm{kg}_{\text {plant }}^{-1}\right)\end{array}$ & $\begin{array}{l}\text { Pre-anthesis } \\
\text { WU } \\
\left.\text { (kg plant }^{-1}\right)\end{array}$ & $\begin{array}{l}\text { Post-anthesis } \\
\text { WU } \\
\left(\text { kg plant }^{-1}\right)\end{array}$ & $\begin{array}{l}\text { TE } \\
\left(\mathrm{g} \mathrm{kg}^{-1}\right. \\
\text { WU) }\end{array}$ & PNHI \\
\hline \multirow[t]{19}{*}{ HPww } & 1 & & 0.65 & 23.38 & 59.92 & 27.04 & 12.09 & 14.95 & 2.12 & 0.69 \\
\hline & 2 & $\mathrm{~T}$ & 0.45 & 6.31 & 52.03 & 29.31 & 15.16 & 14.15 & 1.73 & 0.28 \\
\hline & 3 & $\mathrm{~T}$ & 0.53 & 15.07 & 38.05 & 19.90 & 7.32 & 12.57 & 1.92 & 0.64 \\
\hline & 4 & & 0.49 & 9.89 & 49.32 & 28.71 & 19.94 & 8.77 & 1.77 & 0.43 \\
\hline & 5 & & 0.59 & 19.46 & 50.24 & 25.39 & 11.48 & 13.91 & 1.91 & 0.72 \\
\hline & 6 & $\mathrm{~T}$ & 0.44 & 8.15 & 35.41 & 19.90 & 12.59 & 7.31 & 1.78 & 0.44 \\
\hline & 7 & $\mathrm{~T}$ & 0.50 & 17.16 & 52.76 & 26.92 & 8.66 & 18.26 & 1.85 & 0.50 \\
\hline & 8 & & 0.41 & 8.08 & 48.01 & 26.45 & 20.80 & 5.65 & 1.80 & 0.37 \\
\hline & 9 & $\mathrm{~S}$ & 0.51 & 4.93 & 38.09 & 21.89 & 15.93 & 5.96 & 1.82 & 0.23 \\
\hline & 10 & $\mathrm{~S}$ & 0.55 & 13.14 & 66.09 & 35.48 & 21.12 & 14.36 & 1.80 & 0.40 \\
\hline & 11 & & 0.68 & 13.53 & 45.98 & 24.58 & 11.55 & 13.03 & 1.86 & 0.50 \\
\hline & 12 & & 0.44 & 11.79 & 36.41 & 19.33 & 7.33 & 12.00 & 1.85 & 0.57 \\
\hline & 13 & & 0.52 & 18.90 & 59.41 & 29.81 & 17.06 & 12.75 & 1.97 & 0.59 \\
\hline & 14 & $\mathrm{~S}$ & 0.47 & 9.60 & 58.54 & 31.77 & 17.34 & 14.42 & 1.80 & 0.30 \\
\hline & 15 & & 0.54 & 11.64 & 51.18 & 29.60 & 16.49 & 13.11 & 1.66 & 0.38 \\
\hline & LSD & n.s. & n.s. & n.s. & n.s. & n.s. & n.s. & n.s. & n.s. & \\
\hline & mean & $\mathbf{T}$ & 0.48 & 11.67 & 44.56 & 24.01 & 10.93 & 13.07 & 1.82 & 0.47 \\
\hline & mean & $\mathbf{S}$ & 0.51 & 9.23 & 54.24 & 29.71 & 18.13 & 11.58 & 1.80 & 0.31 \\
\hline & & & n.s. & n.s. & n.s. & n.s. & $p<0.001$ & n.s. & n.s. & n.s. \\
\hline \multirow[t]{22}{*}{ HPws } & 1 & & 0.66 & 8.97 & 40.11 & 22.74 & 11.86 & 10.88 & 1.70 & 0.52 \\
\hline & 2 & $\mathrm{~T}$ & 0.62 & 6.48 & 32.78 & 20.14 & 11.08 & 9.07 & 1.61 & 0.32 \\
\hline & 3 & $\mathrm{~T}$ & 0.68 & 7.37 & 28.83 & 18.32 & 7.57 & 10.74 & 1.54 & 0.41 \\
\hline & 4 & & 0.49 & 2.31 & 31.08 & 19.72 & 15.36 & 4.36 & 1.49 & 0.14 \\
\hline & 5 & & 0.56 & 6.20 & 30.24 & 19.35 & 10.97 & 8.39 & 1.55 & 0.30 \\
\hline & 6 & $\mathrm{~T}$ & 0.48 & 3.12 & 30.43 & 19.25 & 12.28 & 6.96 & 1.58 & 0.18 \\
\hline & 7 & $\mathrm{~T}$ & 0.51 & 6.18 & 26.34 & 16.56 & 8.33 & 8.23 & 1.56 & 0.39 \\
\hline & 8 & & 0.57 & 3.27 & 31.99 & 20.19 & 12.72 & 7.47 & 1.59 & 0.22 \\
\hline & 9 & $\mathrm{~S}$ & 0.42 & 0.71 & 26.39 & 19.62 & 16.89 & 2.73 & 1.35 & 0.06 \\
\hline & 10 & $\mathrm{~S}$ & 0.64 & 5.04 & 38.29 & 23.34 & 13.46 & 9.88 & 1.64 & 0.32 \\
\hline & 11 & & 0.48 & 6.24 & 39.40 & 23.64 & 13.31 & 10.33 & 1.62 & 0.30 \\
\hline & 12 & & 0.56 & 4.36 & 28.29 & 18.98 & 11.05 & 7.93 & 1.47 & 0.33 \\
\hline & 13 & & 0.53 & 4.33 & 34.48 & 20.55 & 14.55 & 6.00 & 1.67 & 0.24 \\
\hline & 14 & $\mathrm{~S}$ & 0.42 & $\mathrm{~N}$ & 32.36 & 21.07 & 14.67 & 5.64 & 1.53 & $\mathrm{~N}$ \\
\hline & 15 & & 0.44 & 3.55 & 28.87 & 19.01 & 12.70 & 6.31 & 1.50 & 0.23 \\
\hline & LSD & $0.22 * * *$ & $6.28^{* *}$ & n.s. & n.s. & $7.21 *$ & $6.99 *$ & n.s. & $0.35^{*}$ & \\
\hline & mean & $\mathbf{T}$ & 0.57 & 5.79 & 29.59 & 18.57 & 9.82 & 8.75 & 1.57 & 0.32 \\
\hline & mean & $\mathbf{S}$ & 0.49 & 2.87 & 32.35 & 21.34 & 15.01 & 6.08 & 1.50 & 0.19 \\
\hline & & & n.s. & $p<0.05$ & n.s. & n.s. & $p<0.001$ & n.s. & n.s. & $p<0.05$ \\
\hline & HPww & & $0.52 \pm 0.02$ & $12.7 \pm 1.03$ & $49.4 \pm 2.39$ & $26.4 \pm 1.05$ & $14.3 \pm 0.78$ & $12.1 \pm 0.72$ & $1.84 \pm 0.03$ & $0.47 \pm 0.03$ \\
\hline & HPws & & $0.54 \pm 0.02$ & $4.5 \pm 0.54$ & $32.0 \pm 1.34$ & $20.2 \pm 0.58$ & $12.5 \pm 0.48$ & $7.7 \pm 0.5$ & $1.56 \pm 0.03$ & $0.28 \pm 0.27$ \\
\hline & G & & $p<0.05$ & $p=0.06$ & n.s. & n.s. & $p<0.05$ & n.s. & n.s. & $p<0.01$ \\
\hline
\end{tabular}


Table 4 (continued)

\begin{tabular}{|c|c|c|c|c|c|c|c|c|c|}
\hline Genotype & Type & $\begin{array}{l}\text { Flag leaf } \\
\text { P conc } \\
\left(\mathrm{mg} \mathrm{g}^{-1} \mathrm{DM}\right)\end{array}$ & $\begin{array}{l}\text { Grain } \\
\text { yield } \\
(\mathrm{g})\end{array}$ & $\begin{array}{l}\text { Tot DM } \\
(\mathrm{g})\end{array}$ & $\begin{array}{l}\text { Total } \\
\text { WU } \\
\left(\operatorname{kg~plant~}^{-1}\right)\end{array}$ & $\begin{array}{l}\text { Pre-anthesis } \\
\text { WU } \\
\left(\mathrm{kg} \mathrm{plant}^{-1}\right)\end{array}$ & $\begin{array}{l}\text { Post-anthesis } \\
\text { WU } \\
\left(\mathrm{kg} \mathrm{plant}^{-1}\right)\end{array}$ & $\begin{array}{l}\text { TE } \\
\left(\mathrm{g} \mathrm{kg}^{-1}\right. \\
\text { WU) }\end{array}$ & PNHI \\
\hline $\mathbf{W}$ & & n.s. & $p<0.001$ & $p<0.001$ & $p<0.001$ & $p<0.05$ & $p<0.001$ & $p<0.001$ & $p<0.001$ \\
\hline GxW & & $p<0.05$ & n.s. & n.s. & n.s. & n.s. & n.s. & n.s. & n.s. \\
\hline
\end{tabular}

$T$ and $S$ are tolerant and sensitive genotypes selected according to their contrasting performance across LPww and LPws. Water use refers to transpiration. Parameters include P concentration measured in the flag leaf ( $\mathrm{mg} \mathrm{g}^{-1}$ dry matter), grain yield (g), total dry matter (g), total WU (total water used during the trial), pre-anthesis WU (water used before flowering), post-anthesis WU (water used after flowering), TE (transpiration efficiency) and PNHI (panicle harvest index). One-way ANOVA was used to determine least significant differences (LSDs) and differences between T and S genotypes. Two-way ANOVA was used to test differences among genotypes (Geno), between water treatments $(\mathrm{W})$ and genotype-by-W treatment $(\mathrm{GxW})$ interaction. Different levels of significance $(p<0.05 *, p<0.01 * *, p<0.001 * * *)$ have been considered. n.s.: not significant

flowering of sensitive genotypes (Suppl. Table 1). During the post-anthesis period in Exp. 2, sensitive lines used $35 \%$ less water under LPww and $45 \%$ less water under LPws than in tolerant lines, which reflected the flowering time differences in the sensitive lines. Sensitive varieties indeed flowered 8 days later under HP conditions and then 10 days later under LP than tolerant ones (Table 3). Tolerant genotypes transpired less before flowering mainly because of earlier flowering under low P. This was especially the case for genotypes 3 and 7 , which transpired the lowest amount of water of all genotypes at this stage $\left(4.7 \mathrm{~kg}\right.$ plant $^{-1}$ and $5.3 \mathrm{~kg} \mathrm{plant}^{-1}$, respectively) and transpired the most after flowering $\left(9.1 \mathrm{~kg} \mathrm{plant}^{-1}\right.$ and $13.2 \mathrm{~kg}$ plant $^{-1}$, Table 3). The water transpired postanthesis was related to higher grain yield, HI and panicle HI in LP (Figs. 5 and 6), further highlighting the importance of water availability for grain filling. The HP treatment did not change this observation: tolerant genotypes still extracted less water in the pre-anthesis period than sensitive ones, but the HP treatment aggravated the effect of water stress in sensitive genotypes and led to a lower water extraction under water stress $(20.2 \mathrm{~kg})$ than under well watered conditions $(26.4 \mathrm{~kg})$. In contrast to $\mathrm{LP}$, no genotypic variation in post-anthesis water use was observed under HP (Table 4).

\section{Transpiration efficiency (TE)}

Phosphorus supply increased TE. Transpiration efficiency values increased from LP conditions to HP, from 1.4 to 1.8 under ww conditions $(p<0.05)$ and from 1.4 to 1.6 under ws conditions $(p<0.05)$. Average TE of sensitive genotypes was significantly more affected by $P$ deficiency (LP) than average TE of tolerant genotypes under both $\mathrm{ww}$ and ws conditions (Fig. 7). A negative relationship was present between the ratio TE under HP/TE under LP and grain yield under ww conditions $(\mathrm{r}=0.591, p<0.05)$. This indicated that a lower TE decrease in the LP treatment was related to a higher grain yield under LP. Under LPww and LPws, TE was positively correlated with grain yield, highlighting again genotypes 3 and 7 with highest TE and high yield (Fig. 8, Table 3).

\section{Seed size}

Grain yield was positively related to seed size in Exp. 1: LP $(\mathrm{r}=0.840, p<0.001)$ and HP $(\mathrm{r}=0.781, \mathrm{p}<0.001)$; and in Exp. 2: $\mathrm{LP}(\mathrm{r}=0.835, p<0.001)$ and $\mathrm{HP}(\mathrm{r}=0.767$, $p<0.001)$, across water treatments. Again, $\mathrm{P}$ played a major role in seed filling as $\mathrm{P}$ stressed plants produced smaller seeds. Moreover, the seeds size of water stressed HP plants (100 seed weight $=0.26 \mathrm{~g})$ was half as large as that of well watered HP plants $(100$ seed weight $=0.61 \mathrm{~g})$ (Table $2 \mathrm{~b}$ and $\mathrm{c})$. At LPww, the 100-seed weight of genotypes 3 and 7 was twice as much as the average of the other genotypes. This did not happen under HPww, where the 100-seed weight of genotypes 12, 5 and 1 was higher or similar to that of genotypes 3 and 7, which indicate a specific effect of the low $\mathrm{P}$ treatment on the filling of the seeds. Under combined stresses (LPws) TE was positively related to seed size, i.e. high TE genotypes were able to better fill the grains $(\mathrm{r}=0.680, p<0.05$, data not 
Grain Yield (g)

a)

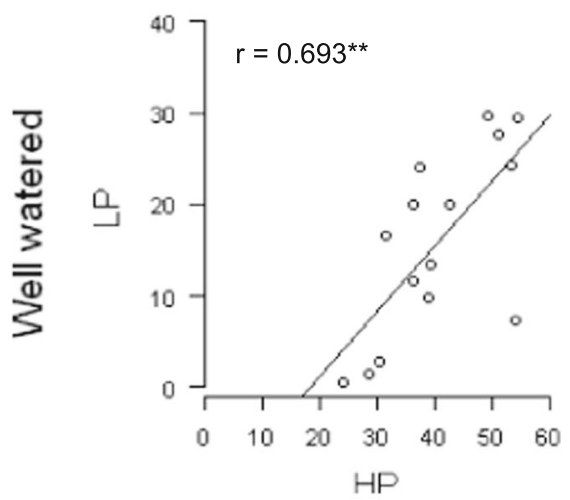

b)

c)

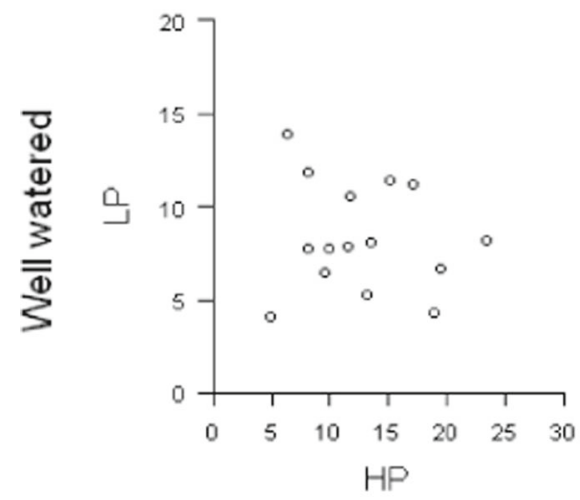

Grain Yield (g)

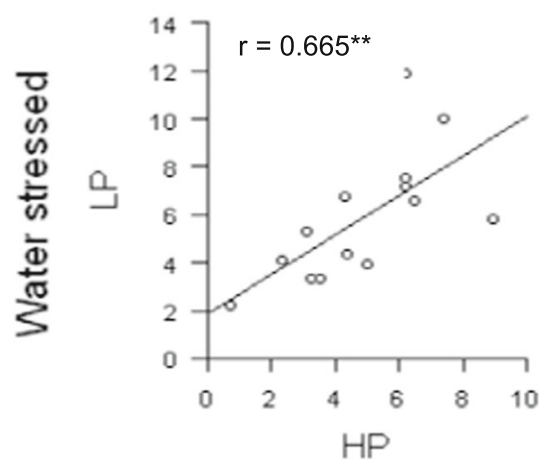

Fig. 1 Relationship between yield under low $\mathrm{P}$ (LP) and high $\mathrm{P}$ (HP) in Experiment 1 conducted at ICRISAT Sahelian Centre (Sadoré) in 2010 under well watered (a) conditions and

shown). This relationship was less clear in the other treatments.

The ratio between the size of the seeds that were sown and the size of harvested seeds under LPww revealed a 28 -fold variation among the 15 genotypes. Moreover, this ratio was strongly and negatively
Stover Yield (g)

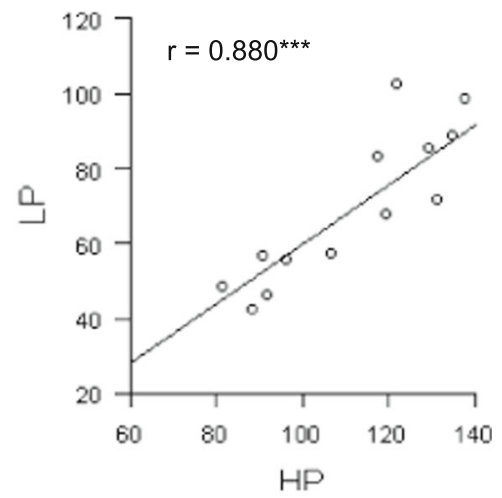

Stover Yield (g)

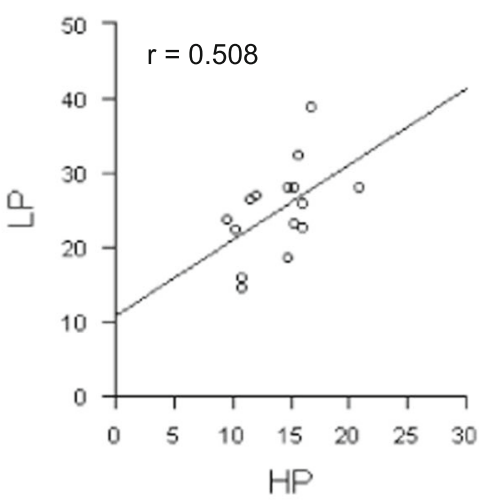

Stover Yield (g)

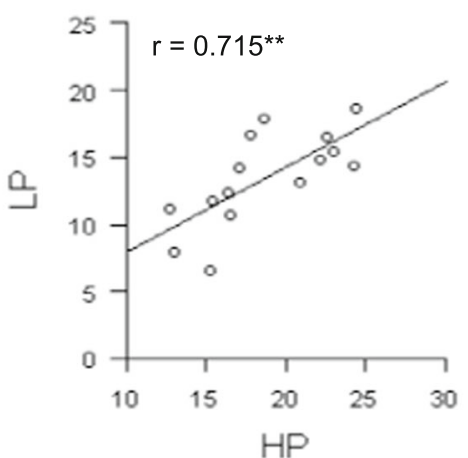

Experiment 2 in 2012 under well watered (b) and water stressed (c) conditions. The values are the means of 15 pearl millet genotypes across repetitions

associated with grain yield under LPww $(r=0.839$, $p<0.001$, Fig. 9), indicating that sensitivity to LP treatment was related to an important decrease in seed filling of the low yielding genotypes.

In summary, the low P treatment decreased the size of the seeds, especially in sensitive genotypes. The water 
Fig. 2 Relationship between residual grain yield and delay in $50 \%$ booting (closed symbols) or flowering (open symbols) for Exp. 1 in 2010. Residual grain yield is the difference between the observed value under LP and the predicted value by the regression line LP vs HP. High residuals are used as proxy for high plant tolerance to low P. Delay in booting or flowering was calculated as the difference between the number of days to boot or flower in LP and those in HP treatments
LP - 2010

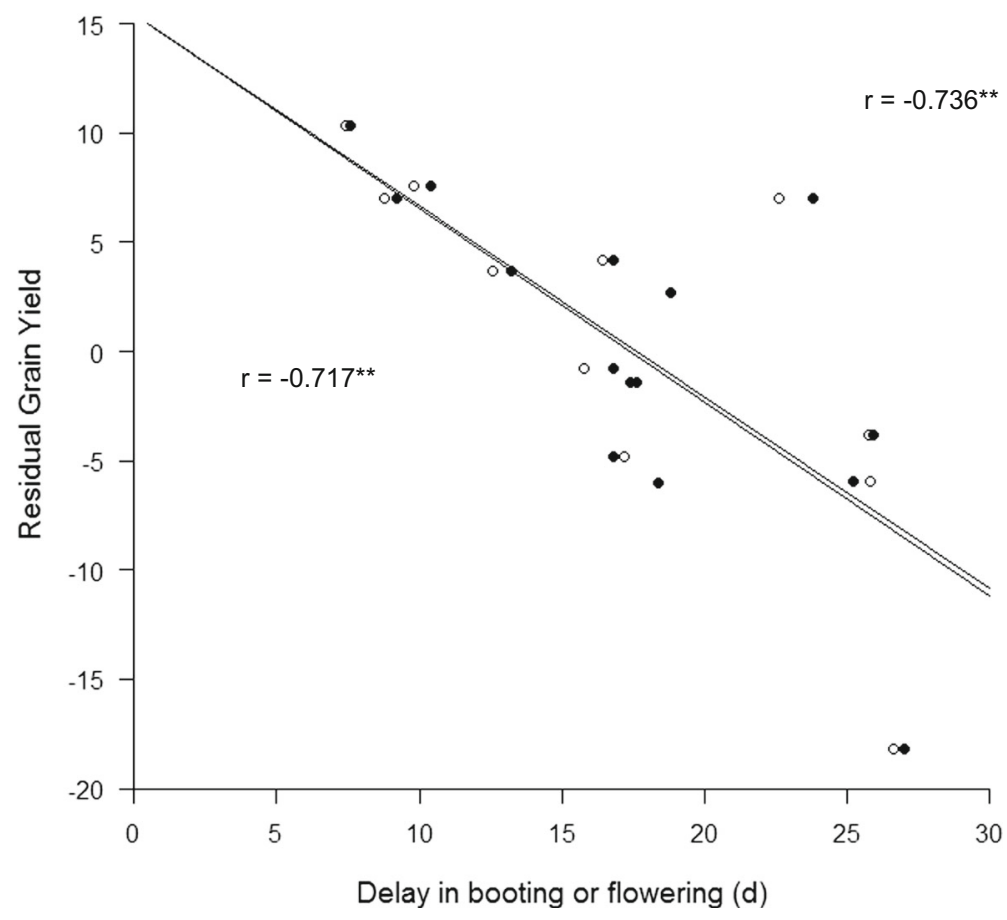

stress treatment further decreased the seed size, and more so in the HP treatment where the water stress had a more severe effect.

\section{Discussion}

Agronomic aspects

As expected, $\mathrm{P}$ deficiency had a deleterious effect on plant growth and biomass production, which ultimately affected seed size at harvest. Smaller seed size means that fewer reserves are stored for plant establishment and less food is produced since grain yield was positively correlated with seed size in our trials. The LP treatment effect during seed filling overrode the effect of the size of planted seeds, i.e. at a given seed size at sowing the most tolerant genotypes were those that maintained a seed size closer to the one in the HP treatment (genotypes 3 and 7; Fig. 9). This in itself could be taken as a simple proxy for selecting tolerant and sensitive genotypes, and this proxy would be independent of the water stress effect since the relationship of Fig. 9 takes place under WW conditions.

The positive effect of $\mathrm{P}$ supply on grain yield was only evident under ww conditions. Under water stressed conditions, $\mathrm{P}$ fertilized plants were larger and they would have run short of water quicker, being therefore more exposed to terminal water stress. In this way their final seed/biomass production did not differ from LPws plants. The lysimeter system we used magnified an effect that might have been different under field conditions, where larger plant spacing would have made more soil available to the plants to explore for water. Water was identified as the key factor for the grain production, because at both $\mathrm{P}$ levels the watering regime explained the largest difference in grain yield. In contrast, the $\mathrm{P}$ treatment was the most important determinant of vegetative biomass production (final dry matter and total yield).

Interestingly, genotypes 2, 3 and 7 confirmed the outcome of the pot trial that was run to identify low $\mathrm{P}$ sensitivity or tolerance and from which these lines were originally selected before being planted in lysimeters. In particular, the genotype 3 had one of the highest $\mathrm{P}$ efficiency $(43.2 \%$, i.e. ratio between vegetative biomass produced under low $\mathrm{P}$ and biomass produced under high P) (unpublished data). Previous work indicated that the tolerant genotypes had different strategies to cope with low P: genotypes 3 and 7 had significantly longer roots than genotype 2 at 5 WAS (Beggi et al., unpublished). Genotype 3 accumulated three times more $P$ than lines 2 or 7 , showing a peak in arbuscular mycorrhizal (AM) 

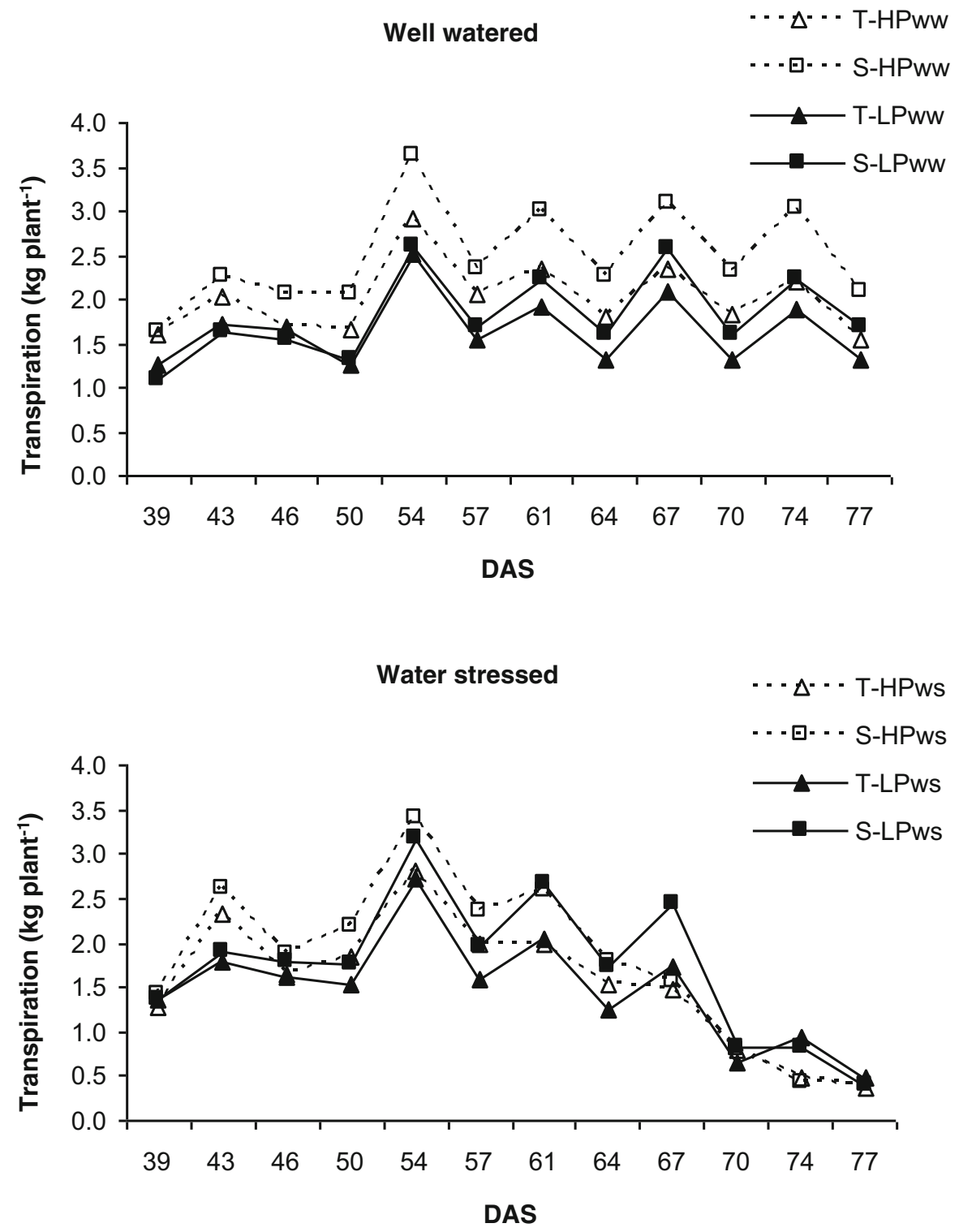

Fig. 3 Water uptake over time (days after sowing, DAS) of pearl millet under well watered (above) and water stressed (below) conditions. Different lines represent LP and HP treatments of 4

colonization at 4 WAS, whereas line 2 did not show any important infection of AM (unpublished data). The sensitive varieties used in this study also had a low $\mathrm{P}$ efficiency when grown in pots, as well as variety 6 which was here selected as tolerant.

Flowering delay

Severe water deficit during the period of panicle development or P deficiency are known to delay flowering in low P tolerant (T) and 3 low P sensitive (S) genotypes. Irrigation was suspended in ws treatments at 56 DAS and restarted at 74 DAS

pearl millet (Mahalakshmi and Bidinger 1985; Karanam and Vadez 2010). Phenological delay has often been reported as an adaptive response of annual plants to P-deficiency because it increases the duration of nutrient uptake (Nord and Lynch 2008). This, however, assumes there is no water limitation later in the growing season. For pearl millet grown under Sahelian conditions, delayed flowering would indeed increase the risk of the plant encountering water deficient conditions 


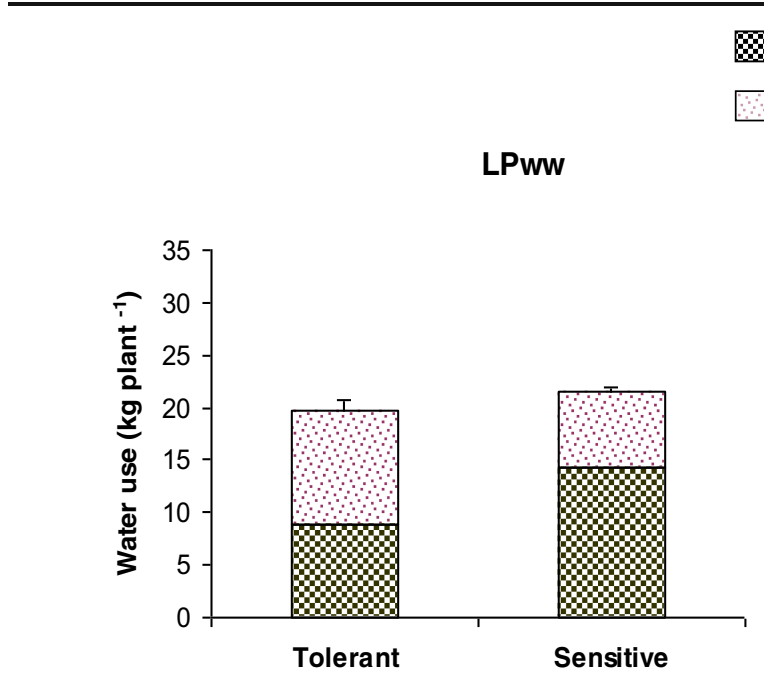

Pre-anthesis

Post-anthesis

LPws

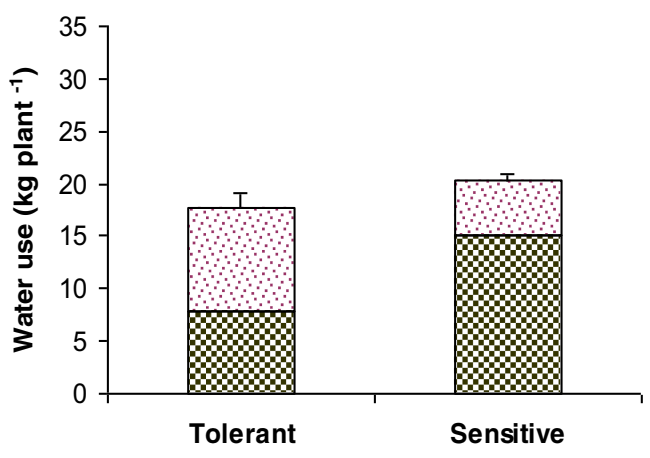

Fig. 4 Water use in the pre-anthesis and post-anthesis period in Exp.2. Dat are the mean of the values for 4 tolerant and 3 sensitive pearl millet genotypes, selected from their yield difference contrast under LPww conditions. Plants were grown in lysimeters under

during grain filling at the end of the rains and of grain filling occuring solely under residual moisture. That is why it is generally accepted that annual plants flower and mature earlier to avoid late-season water stress (Thies et al. 1995; Dorn et al. 2000; Gungula et al. 2003). In contrast to previous findings, the data from our first trial show that genotypes sensitive to low $\mathrm{P}$ had a larger delay in flowering under LP. This indicates that a delay in booting or flowering decreased pearl millet's tolerance to low $\mathrm{P}$ conditions and the greatest reproductive success was observed in pearl millet genotypes that flowered earlier under P deficiency. This could not be tested adequately in Experiment 2 that was carried out under short days and would require additional research on a potentially quite important result.

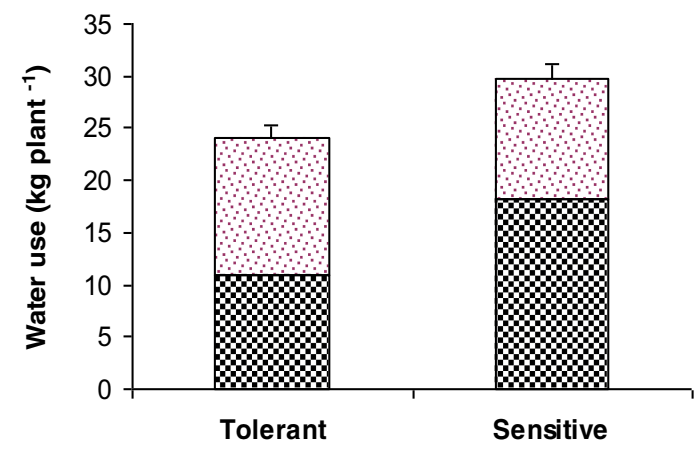

HPws

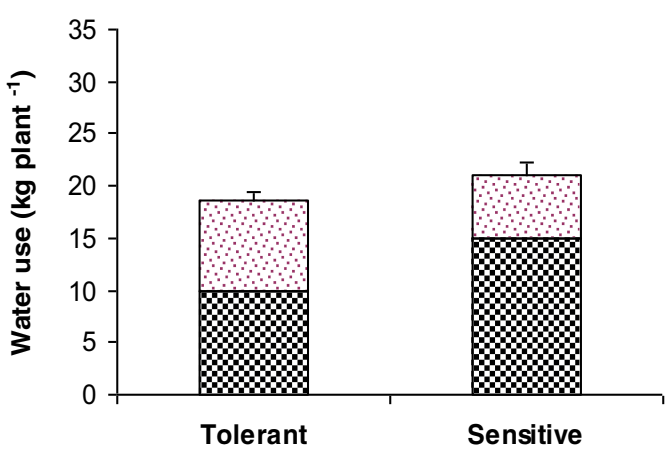

ww (well watered, above) and ws (water stressed, below) treatments. No significant differences were observed when comparing total water use (pre- plus post-antithesis water use)

Water use kinetics

Varieties tolerant to low $\mathrm{P}$ - i.e. having higher yields under LPww- used the same total amount of water during the cropping cycle as low P sensitive ones, which yielded less. Thus the total water extraction capacity of the root system did not seem to be responsible for the tolerance differences, which is in agreement with a similar study in chickpea (Zaman-Allah et al. 2011). Rather, what differed between tolerant and sensitive varieties in our experiment was the pre- and postanthesis pattern of water use. Tolerant varieties had higher post-anthesis water use while sensitive ones transpired more water during vegetative stage, leaving less water available for the grain filling stage. As tolerant genotypes flowered earlier, the relative shorter duration 
Fig. 5 Relationship between grain yield and water use in the post-anthesis period. Data are the means of 15 pearl millet genotypes grown in lysimeters conditions (above) and under LPws (low P water stressed) conditions (below) in Exp. 2 under LPww (low P well watered)

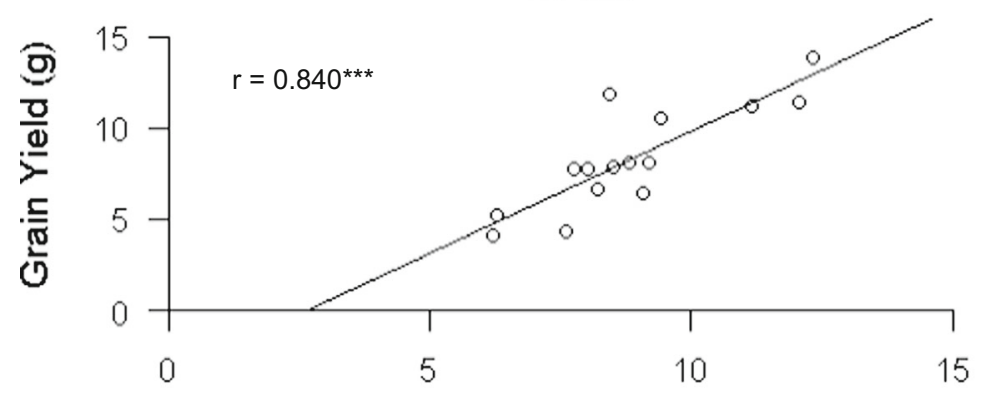

LPws

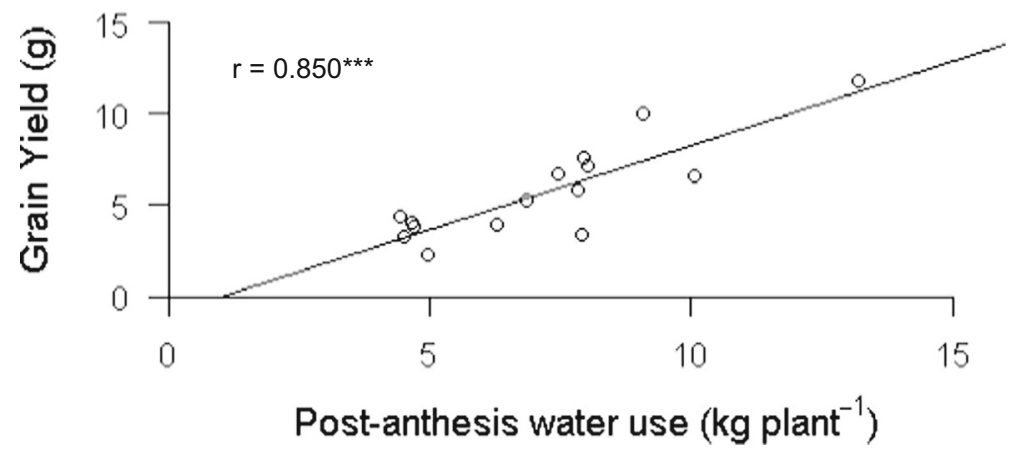
water use in the post-anthesis period and the harvest index (HI) (open symbols) or panicle $\mathrm{HI}$ (closed symbols). Data are the means of 15 pearl millet genotypes grown in lysimeters under LPww (low P well watered) in Exp. 2
LPww

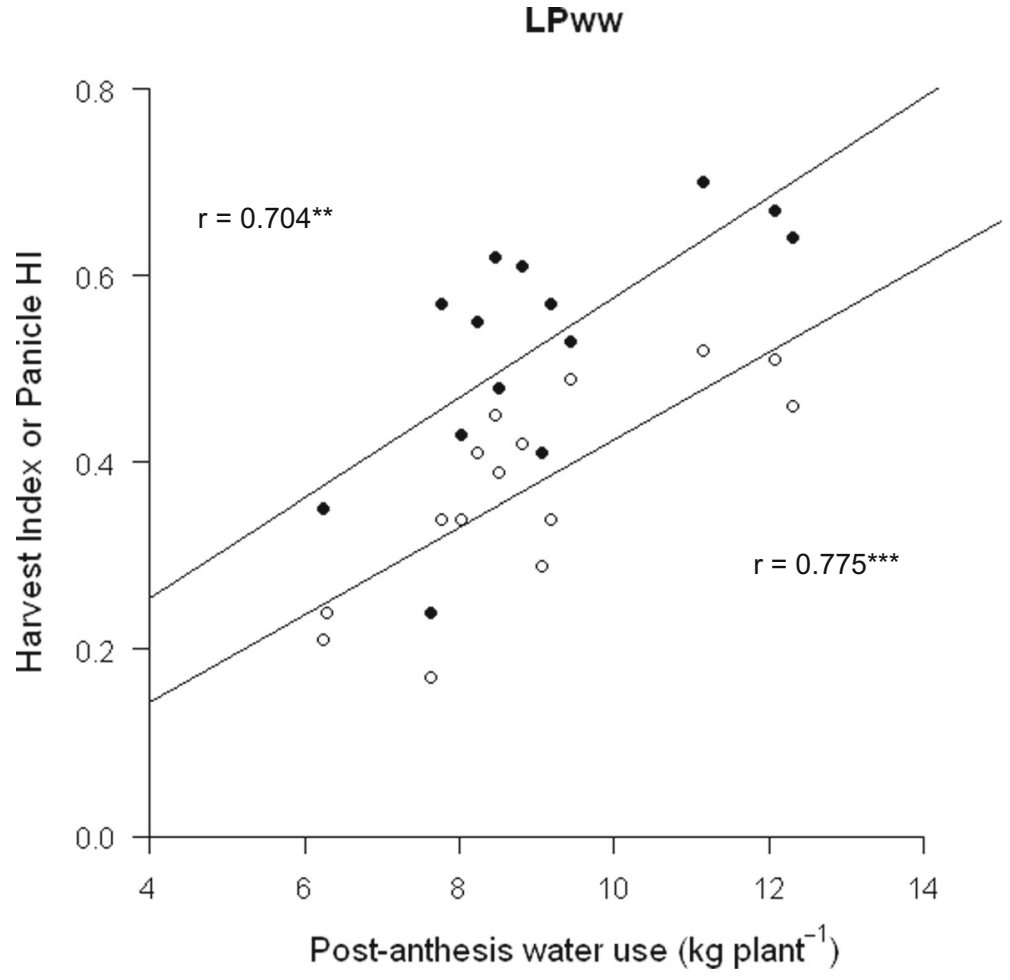



four tolerant $(\mathrm{T})$ and three sensitive (S) pearl millet genotypes grown in lysimeters under four treatments with different availability of P (LP: low $\mathrm{P}$ and HP: high $\mathrm{P}$ ) and water (ws: water stressed and ww: well watered) in Exp. 2
Fig. 7 Transpiration efficiency of

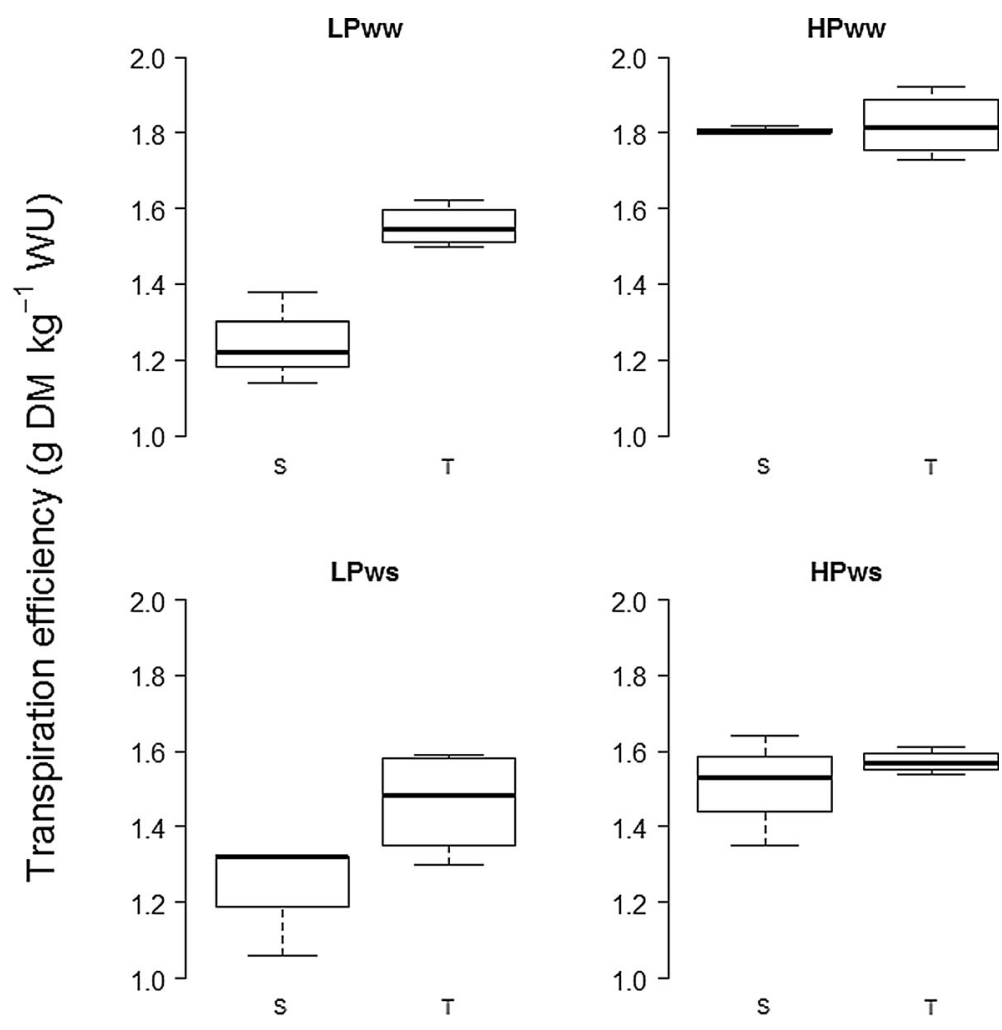

Transpiration efficiency

of the low $\mathrm{P}$ tolerant than the low $\mathrm{P}$ sensitive genotypes could have explained in part a stronger effect of the water stress in the sensitive genotypes. However, the second experiment, set in short days, did not allow us to confirm the results from Exp.1 of a delayed flowering being related to lower yield under low soil P (Fig.1a). This confirms very recent findings in pearl millet hybrids, of a strong positive relationship between soil available water under water stress and grain yield (Vadez et al. 2013). However, more research would be needed to assess whether low soil $\mathrm{P}$ can aggravate this by delaying flowering further in low $\mathrm{P}$ sensitive genotypes. Previous results stress the decisive role of water availability during grain filling (Merah 2001; Kato et al. 2008). We observed this trend in both low $\mathrm{P}$ and high $\mathrm{P}$ treatments, indicating no major role of $\mathrm{P}$ in the trend, although the delay in booting under low soil $\mathrm{P}$ in sensitive material would simply exacerbate that trend. Differences between pre- and post-anthesis water extraction were independent of water availability, suggesting that a constitutive mechanism (not activated by stress) giving an advantage in terms of stress avoidance might have played a role there, such as previously found for pearl millet in India (Kholová et al. 2010a; b).
Improved water use efficiency represents one major avenue to enhance crop productivity under limited water supply. In our study, the application of P improved TE, thus confirming what was reported in literature (Payne 2000) and what was hypothesized here. Different authors (Tanner and Sinclair 1983; Gregory 1989; Schmidhalter and Studer 1998) have concluded that TE is mostly affected by atmospheric evaporative demand and the $\mathrm{CO}_{2}$ pathway, while TE was only affected by severe nutrient limitation, which is unfortunately the case for $\mathrm{P}$ under on-farm conditions of the West African Sahel. Payne and colleagues (1992) found similar results by growing pearl millet in pots, i.e. TE increased for increasing levels of $\mathrm{P}$ availability. Our findings showed that tolerant genotypes produced higher yields under combined $\mathrm{P}$ and water stress, had higher TE under low $\mathrm{P}$ conditions, while the total amount of water used was similar compared with sensitive genotypes. These results add to a recent review that argues that high TE can indeed be related to higher grain yield (Vadez et al. 2014). More research would be needed to understand the mechanisms underlying the TE differences occuring 
Fig. 8 Relationship between grain yield and transpiration efficiency of 7 pearl millet genotypes (4 tolerant and 3 sensitive) grown in lysimeters under LPww (low P well watered) and LPws (low P water stressed) conditions in Exp. 2
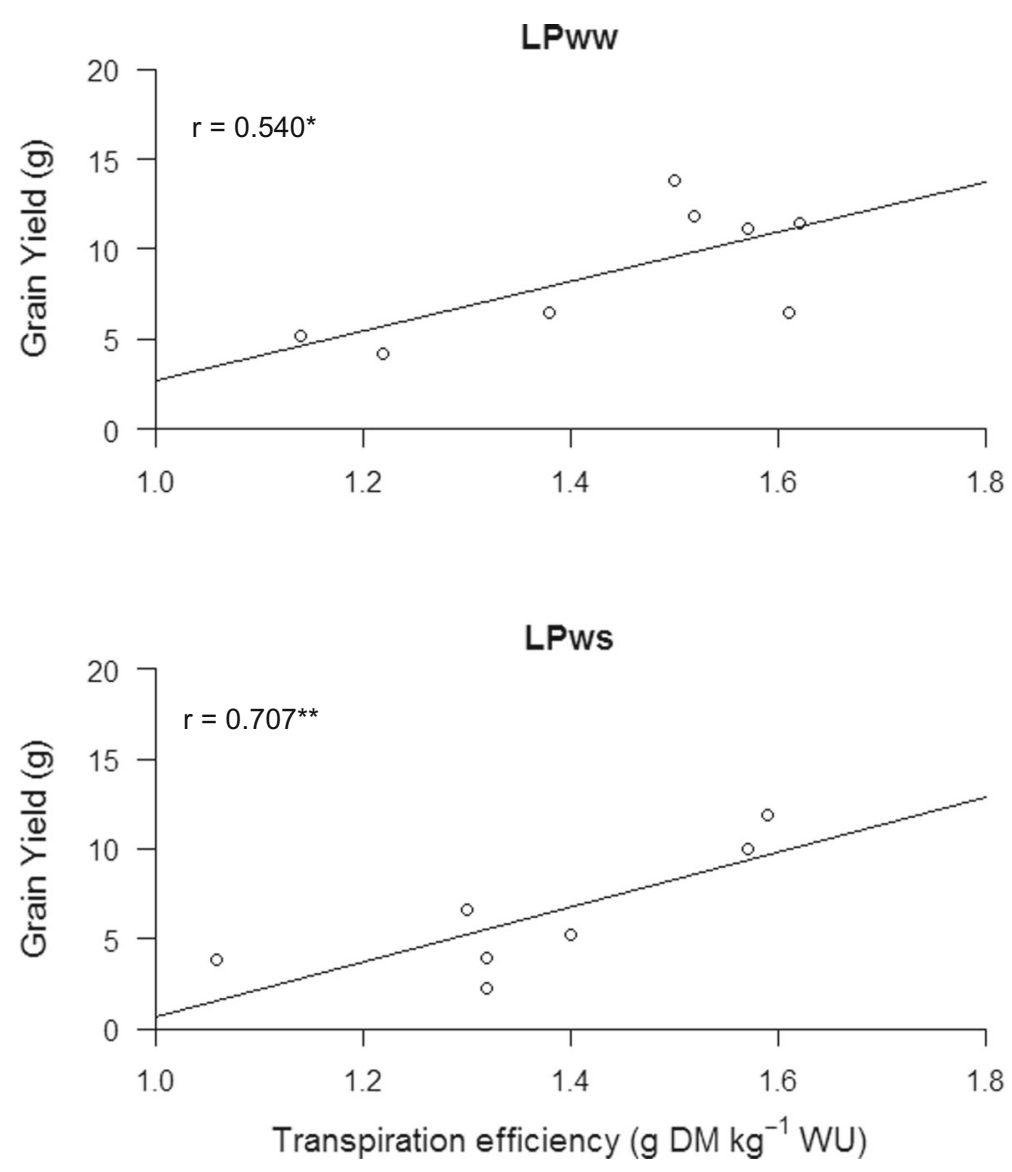

between tolerant and sensitive genotypes under low soil P.

Both of our trials were conducted under high evaporative demand and it is known that there are genotypic
Fig. 9 Relationship between grain yield and the ratio between the size of seeds that were sown and harvested under LPww (low $P$ well watered) conditions. Data are the means of 15 pearl millet genotypes grown in lysimeters in Exp. 2

\section{(LPWW)}

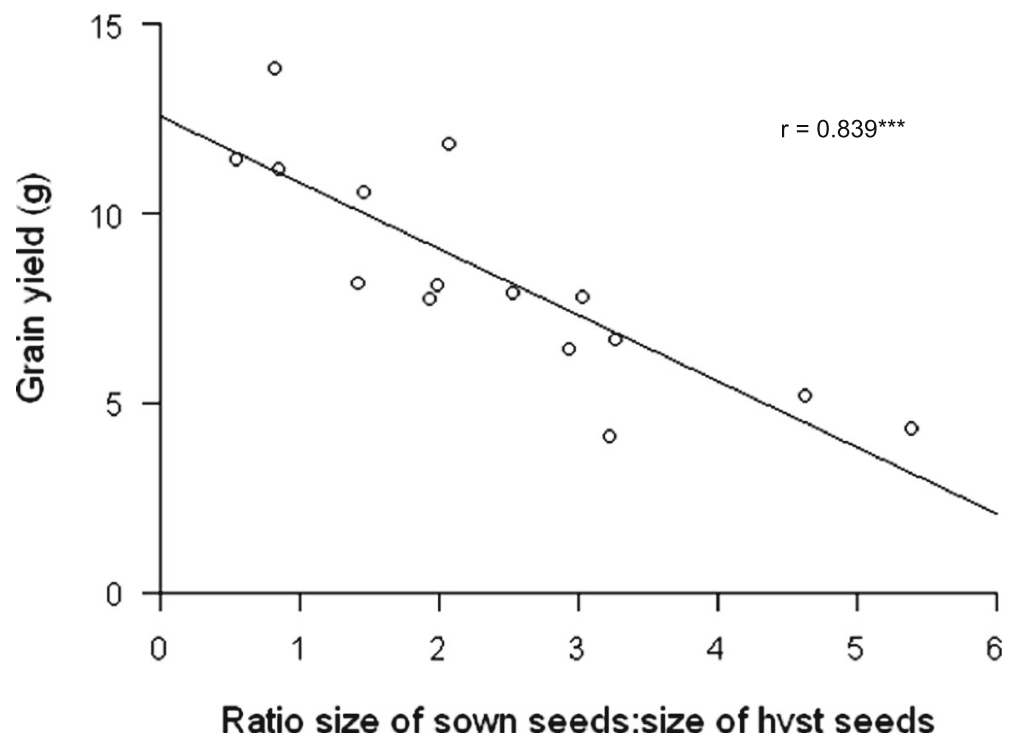


differences in pearl millet for their transpiration response to high VPD (Kholová et al. 2010a; b). At this stage we can only speculate how the low P conditions could have altered the way in which transpiration responds to high VPD. This deserves additional detailed work. Upon these considerations and according to the water use kinetics that we have seen, $\mathrm{P}$ also plays a role as it increases the amount of dry matter produced per unit water transpired, and so it could be that $\mathrm{P}$ amplifies the beneficial effect of water uptake at a key stage in plant development.

\section{Conclusions}

Our results showed that tolerant pearl millet genotypes had more conservative water use (they transpired relatively more water during the post-anthesis period), their delay in flowering under low soil $\mathrm{P}$ was less, their seed size was less decreased under low soil $\mathrm{P}$, and they had a lower TE decrease under low soil $\mathrm{P}$ than in sensitive genotypes. This leaves us with a basket of option for pre-screening of potentially interesting materials for low soil $\mathrm{P}$ conditions. In addition, it opens necessary research actions, especially on the need to understand / confirm a possible effect of low soil $\mathrm{P}$ on the delay in flowering (longer phyllochron? Increase in leaf number?), and on TE (differences in the response of transpiration to high VPD between low and high soil P conditions?). These questions are currently the object of additional studies.

\begin{abstract}
Acknowledgments The authors are grateful to Bundesministerium fur wirtschaftliche Zusammenarbeit und Entwicklung (BMZ) for its financial support within the collaborative project "Tackling Abiotic Production Constraints in pearl millet and sorghum-based agricultural systems of the West African Sahel' (GIZ Project Number 09.7860.1-001.00). Part of the funding provided also from the CGIAR Research Program on Dryland Cereals. We thank Dr. Charles Thomas Hash for providing scientific support and research facilities, and finally the technician Hassane Abdou and the workers at ICRISAT Sahelian Centre at Sadoré for their great commitment in conducting the lysimeter measurements.
\end{abstract}

Open Access This article is distributed under the terms of the Creative Commons Attribution License which permits any use, distribution, and reproduction in any medium, provided the original author(s) and the source are credited.

\section{References}

Bagayoko M, George E, Roemheld V, Buerkert A (2000) Effects of mycorrhizae and phosphorus on growth and nutrient uptake of pearl millet, cowpea and sorghum on a West African soil. J Agric Sci 135:399-407

Barry DAJ, Miller MH (1989) Phosphorus nutritional requirement of maize seedlings for maximum yield. Agron J 81:95-99

Bationo A, Chien SH, Henao J, Christianson CB, Mokwunye AU (1990) Agronomic evaluation of two unacidulated and partially acidulated phosphate rocks indigenous to Niger. Soil Sci Soc Am J 54:1772-1777

Belko N, Zaman-Allah M, Diop NN, Cisse N, Ehlers JD, Ndoye O, Zombre G, Vadez V (2012) Lower soil moisture threshold for transpiration decline under water deficit correlates with lower canopy conductance and higher transpiration efficiency in drought tolerant cowpea. Funct Plant Biol 39:306-322. doi:10.1071/FP11282

Bidinger FR, Mahalakshmi V, Rao GDP (1987) Assessment of drought resistance in pearl millet [Pennisetum americanum (L.) Leeke]. II estimation of genotype response to stress. Aust J Agric Res 38:49-59

Bould C, Parfitt RI (1973) Leaf analysis as a guide to the nutrition of fruit crops. X. Magnesium and phosphorus sand culture experiments with apple. J Sci Food Agric 24:175-185

Brück H, Sattelmacher B, Payne WA (2003) Varietal differences in shoot and rooting parameters of pearl millet on sandy soils in Niger. Plant Soil 251:175-185

Buerkert A (1995) Effects of crop residues, phosphorus and spatial soil variability on yield and nutrient uptake of pearl millet (Pennisetum glaucum L.) in S-W Niger. Verlag Ulrich E. Grauer, Stuttgart, 272 pp

Buerkert A, Bationo A, Dossa K (2000) Mechanisms of residue mulch-induced cereal growth increases in West Africa. Soil Sci Soc Am J 64:346-358

Clarkson DT, Carvajal M, Henzler T, Waterhouse RN, Smyth AJ, Cooke DT, Steudle E (2000) Root hydraulic conductance: diurnal aquaporin expression and the effects of nutrient stress. J Exp Bot 51:61-70

De Wit CT (1958) Transpiration and crop yield. Vers1. Landbouwk. Onder. 64(6). Int of Biol And Chem Res On Field Crops and Herbage. Wageningen, the Netherlands

Dorn LA, Pyle EH, Schmitt J (2000) Plasticity to light cues and resources in Arabidopsis thaliana: testing for adaptive value and costs. Evolution 54:1982-1994

FAO, ICRISAT (1996) The world sorghum and millet economies - facts, trends and outlooks, ISBN 92-5-103861-9, 68 pg

Faye I, Diouf O, Guisse A, Sene M, Diallo N (2006) Characterizing root responses to low phosphorus in pearl millet [Pennisetum glaucum (L.) R. Br.]. Agron J 98:1187-1194

Fredeen AL, Rao IM, Terry N (1989) Influence of phosphorus nutrition on growth and carbon partitioning in Glycine max. Plant Physiol 89:225-230

Gahoonia TS, Nielsen NE (2004) Root traits as tools for creating phosphorus efficient crop varieties. Plant Soil 260:47-57

Gregory PJ (1989) Water-use efficiency of crops in the semi-arid tropics. p. 85-89. In "Soil, crop and water management systems for rainfed agriculture in the Sudano-Sahelian zone: Proc. Int. Workshop, Niamey, Niger". 7-11 Jan 1987. Icrisat, Patancheru, A.P., India 
Groom PK, Lamont BB (2010) Phosphorus accumulation in Proteaceae seeds: a synthesis. Plant Soil 334:61-72

Gungula DT, Kling JG, Togun AO (2003) CERES-maize predictions of maize phenology under nitrogen-stressed conditions in Nigeria. Agron J 95:892-899

Hammer GL, Cooper M, Tardieu F, Welch S, Walsh B, Van Eeuwijk F, Chapman S, Podlich D (2006) Models for navigating biological complexity in breeding improved crop plants. Trends Plant Sci 11:587-593

Karanam PV, Vadez V (2010) Phosphorus coating on pearl millet seed in low P Alfisol improves plant establishment and increases stover more than seed yield. Exp Agric 46:457-469

Kato Y, Kamoshita A, Yamagishi J (2008) Preflowering abortion reduces spikelet number in upland rice (Oryza sativa L.) under water stress. Crop Sci 48:2389-2395

Kholová J, Hash CT, Kakkera A, Kočová M, Vadez V (2010a) Constitutive water conserving mechanisms are correlated with the terminal drought tolerance of pearl millet [Pennisetum glaucum (L.) R. Br.]. J Exp Bot 61:369-377

Kholová J, Hash CT, Kumar PL, Yadav RS, Kočová M, Vadez V (2010b) Terminal drought-tolerant pearl millet [Pennisetum glaucum (L.) R. Br.] have high leaf ABA and limit transpiration at high vapour pressure deficit. J Exp Bot 61:14311440

Liao K, Yan X (1999) Seed size is closely related to phosphorus use efficiency and photosynthetic phosphorus use efficiency in common bean. J Plant Nutr 22:877-888

Liebersbach H, Steingrobe B, Claassen N (2004) Roots regulate ion transport in the rhizosphere to counteract reduced mobility in dry soil. Plant Soil 260:79-88

Lynch J, Lauchli A, Epstein E (1991) Vegetative growth of the common bean in response to phosphorus nutrition. Crop Sci $31: 380-387$

Mahalakshmi V, Bidinger FR (1985) Flowering response of pearl millet to water stress during panicle development. Ann Appl Biol 106:571-578

Manu A, Bationo A, Geiger SC (1991) Fertility status of selected millet producing soils of West Africa with emphasis on phosphorus. Soil Sci 152:315-320

Marschner H (1995) Mineral nutrition of higher plants, 2nd edn. Academic, London

Merah O (2001) Potential importance of water status traits for durum wheat improvement under Mediterranean conditions. J Agric Sci 137:139-145

Nord EA, Lynch JP (2008) Delayed reproduction in Arabidopsis thaliana improves fitness in soil with suboptimal phosphorus availability. Plant Cell Environ 31:1432-1441

Orsi CH, Tanksley SD (2009) Natural Variation in an ABC transporter gene associated with seed size evolution in tomato species. PloS Genet 5:e1000347. doi:10.1371/journal.pgen. 1000347

Payne WA (2000) Optimizing crop water use in sparse stands of pearl millet. Agron J 92:808-814

Payne WA, Wendt CW, Lascano RJ (1990) Root zone water balances of three low-input millet fields in Niger, West Africa. Agron J 82:813-819

Payne WA, Drew MC, Hossner LR, Lascano RJ, Onken AB, Wendt CW (1992) Soil phosphorus availability and pearl millet water-use efficiency. Crop Sci 32:1010-1015
Ratnakumar P, Vadez V (2011) Groundnut (Arachis hypogaea) genotypes tolerant to intermittent drought maintain a high harvest index and have small leaf canopy under stress. Funct Plant Biol 38:1016-1023

Schmidhalter U, Studer C (1998) Water-use efficiency as influenced by plant mineral nutrition. 1st Sino-german workshop "Impact of plant nutrition on sustainable agricultural production" Kiel, 22-23.20.1998, 9 pages

Sivakumar MVK, Salaam SA (1999) Effect of year and fertilizer on water-use efficiency of pearl millet (Pennisetum glaucum) in Niger. J Agric Sci 132:139-148

Tanner CB, Sinclair TR (1983) Efficient water use in crop production: research or re-search? In: Taylor HM et al (eds) Limitations to efficient Water Use in Crop Prod. ASA, CSSA and SSSA, Madison, pp 1-27

Thies JE, Singleton PW, Bohlool BB (1995) Phenology, growth and yield of field-grown soybean and bush bean as a function of varying modes of N nutrition. Soil Biol Biochem 27:575583

Vadez V, Krishnamurthy L, Gaur PM, Upadhyaya HD, Hoisington DA, Varshney RK, Turner NC, Siddique KHM (2007) Large variation in salinity tolerance is explained by differences in the sensitivity of reproductive stages in chickpea. Field Crop Res 104:123-129

Vadez V, Krishnamurthy L, Hash CT, Upadhyaya HD, Borrel AK (2011a) Yield, transpiration efficiency, and water use variations and their relationships in the sorghum reference collection. Crop Pasture Sci 62:1-11

Vadez V, Deshpande SP, Kholová J, Hammer GL, Borrel AK, Talwar HS, Hash CT (2011b) Stay-green quantitative trait loci's effects on water extraction, transpiration efficiency and seed yield depend on recipient parent background. Funct Plant Biol 38:553-566

Vadez V, Kholova J, Yadav RS, Hash CT (2013) Small temporal differences in water uptake among varieties of pearl millet (Pennisetum glaucum (L.) R. Br.) are critical for grain yield under terminal drought. Plant Soil 371:447-462

Vadez V, Kholova J, Medina S, Aparna K, Anderberg H (2014) Transpiration efficiency: New insights into an old story. J Exp Bot. doi:10.1093/jxb/eru040

Valluru R, Vadez V, Hash CT, Padmaja K (2009) A minute P application contributes to a better establishment of pearl millet seedling in P-deficient soils. Soil Use Manag 26: 39-43

Wallace JS, Lloyd CR, Sivakumar MVK (1993) Measurements of soil, plant and total evaporation from millet in Niger. Agric For Metereol 63:149-169

Waraich EA, Ahmad R, Ashraf MY, Saifullah AM (2011) Improving agricultural water use efficiency by nutrient management in crop plants. Acta Agric Scand Sect B Soil Plant Sci 61:291-304

World Climate (2008) www.worldclimate.com

Zaman-Allah M, Jenkinson DM, Vadez V (2011) A conservative pattern of water use, rather than deep or profuse rooting, is critical for the terminal drought tolerance of chickpea. J Exp Bot 62:4239-4252

Zhu YG, Se S (2001) Seed phosphorus (P) content affects growth, and $P$ uptake of wheat plants and their association with arbuscular mycorrhizal (AM) fungi. Plant Soil 231:105-112 